ADALVENIZA SIMĀO DA COSTA

AVALIAC,ĀO DO ESTADO NUTRICIONAL DE CRIANCAS DE 1 A 4 ANOS DE IDADE NO MUNICÍPIO DE CARAPICUIBA

\author{
Dissertação de Mestrado apresen \\ tada à Faculdade de Saúde pübli \\ ca da Universidade de Sãopaula \\ Departamento de Nutrição, para \\ obtenção do titulo de "Mestre \\ em Saúde püblical. \\ Orientador: Prof. Dr. Donald Wilson
}

\title{
SĀO PAULO
}

1980

BIBLIOTECA

faCuldade de saúde pIIBI ICA 
DEDICATORIA 
Ao meu pai, NELSON SIMAO DA COSTA e minhas abilhadas, CRISTIANY e IGNES FREITAS.

Em memōria da minha mãe, ANA FILICIO DA COSTA.

Aos Mestres da Faculdade de Saūde Püblica da Universidade de são paulo. 
Ao meu orientador:

PROFESSOR ADJUNTO DOUTOR DONALD WILSON, dO Depar tamento de Nutrição da Faculdade de Saūde Pública da Universidade de São Paulo; se de alguma forma este trabalho oferecer qualquer contribuição para que alguma atividade possa ser melhor realizada este mérito é seu, pelo incentivo, apoio, dedicação, pelo inigualāvel espirito de luta aos proble mas de Saúde pūblica que sempre dirigiram o seu interesse e atenção. 
AGRADECIMENTOS 
- a pRofessora dolutora maria jose roncada do Departamento de Nistrição da Faculdade de saūde püblica da univeroidade de são paulo, pelo apoio, estímulo, revisão da redaçãa e suges tóes dadas.

- AO PROFESSOR DUUTOR yARO RIBEIRO GANDRA, Chefo do Departa nento de Nutrição da Faculdade de Saūde püblica - USP, que tão bem soube nos transmitir através dos seus ensinamentos, sias experiencias e saber.

- A NUTRICIONISTA aldONIA CEKALNASKAS KALIL, pelo incentivo e oportunidade de realizar a presente monografia.

- ás NUTRICIONISTAS bARBARA REgINA LERNER, DORIS IUCIA MARTINI IEl, REgINA GLORIA RAMOS, SANDRA CHAVES GARCIA E ZELIA DE FA RIAS, pelo exemplo de trabalho profissicnal, qie transmitirain atravess da valiosa. colaboração.

- AO PREFEITO SENHOR ANTONIO fAUSTINO dOS sANTOS e funcionários da Prefeitura de Carapicuiba, Luiz Carlos Alves Neves a Maria otilia Jardim, pela valiosa colaboraçâo na base do sen viço de campo.

- Ao Sanitarista.José A. Artāvia Morales, pela ajuda na pímei ra base da pesquisa. 
- Aos Sanitaristas Clodoaldo da Silveira costa e Hilārio Louren ço Freitas Jūnior. pela eficiência em discutir à apresentação das tabelas.

- Ao Amigo Andrew wilson, pela preparação das tabelas e auxilio no material bibliogrä́fico.

- A Nādia Cristina Chain e a "Gamilia maravilhosa", pelo carinho e atenção dispensados, durante todo o nosso curso.

- Aos Docentes, Amigos e Pessoal Técnico-Administrativo da Universidade Federal do Cearā, cujo apoio e incentivo foram fun damentais ao desenvolvimento da nossa atividade cientifica.

- Um agradecimento especial às mães, pré-escolares e pessoal vo luntārio dos postos de distribuição da suplementação alimentar, que nos deram a oportunidade de realizar o nosso trabatho.

- A Bibliotecāria Leda Correa Porto de Campos Camargo, pela revisão final das referências bibliogräbicas.

- Ao Andrade, pelo serviço de datilografia.

- Finalmente, a todos aqueles que colaboraram direto ou indiretamente fazendo com que este trabalho se tornasse realidade. 


\section{N D I $C$ C}

pag。

I - INTRODUÇÃO

II - OBJETIVOS

IV - MATERIAL E METODOS

VI. - CONCLUSOES 


\section{$\begin{array}{llllll}R & E & S & U & M & 0\end{array}$}

A autora estudou-a situação nutricional de crianças de 1 a 4 anos de idade, residentes no município de Carapicuiba - São Paulo, no início da atividade de suplementação alimentar. Estudou também a relação existente entre o estado nutricional do referido grupo etārio com a suplementação ali mentar, nīvel sōcio-econōmico e escolaridade.das mães. Avaîiou num período de 5 meses, às variāveis em estudo, principalmente as referentes ao nīvel sōcio-econōmico, educação alimentar e estado nutricional, bem como as suas modificações e interrelações.

Encontrou que a frequēncia de crianças de 1 a 4 anos de ida de, com algum grau de desnutrição segundo a.classificação de GOMEZ, foi de $37,1 \%$ na primeira fase do estudo, na segunda fase constatou-se uma diminuição nas proporções correspondentes às crianças desnutridas, desaparecendo desnutridas do grau dois $\left(D_{2}\right)$ e permanecendo os dois casos de desnutridos do grau três $\left(D_{3}\right)$.

Encontrou tambēm-que $90,4 \%$ das mães de 217 .prē-escolares estudados, não tinham escolaridade ou apresentavam primeỉro grau incompleto e que neste nīvel se encontravam $47,2 \%$ de crianças desnutridas. A proporção de crianças desnutridas cujas mães tinham segundo grau incompleto foi de $35,4 \%$. No entanto apōs cinco meses de atividade da suplementação alimentar 
quando foj realizado para.lelamente o. programa. de.educação nutricional, a redução de crianças desnutridas para o grupo de mães sem escolaridade foi acentuada e altamente significante.

Quanto a renda constatou que. $53,8 \%$ da população estudada tinha rencia per-capita inferior a dois salārios mínimos.

A autora reíacionando estado nutricional com renda percapita, observou que quanto menor a renda maior a proporçăo de desnutrido. 


\section{$\begin{array}{lllllll}S & U & M & M & A & R & Y\end{array}$}

Nutu tional status of children 1 to 4 years of age resident in the cown of Carapicuiba, São Paulo, Brazil was studied at the begining of supplementation activities and 5 months later. Data were related to age, $\$ 0$. 10-econcme level and scholastic status of mothers.

Results show that $37.1 \%$ children were malnurished at the begining of the study and that there was a reduction of the rate five months later. There was a reduction of II degree malnutrition. However III degree malnurished children did not show any improvement.

Considering scholastic status of mothers, it was found that $90.4 \%$ were either 1117 terate or had not completed primary 5 chool; $42.2 \%$ of the children were malnurished whereas those whose mothers had completed high school.and.had.started college, presented a rate of $35.4 \%$ of malnutrition.

Five months later a higly significant differente of rates was observed in the group whose mothers were illiterate.

Regarding socio-economic status, the "per capita" income of $53.8 \%$ of families was below two "minimum salarjes". (salärio minnimo).

Results showed that the lower the "per capita" income the higher the malnutrition rates. 


\section{I - INTRODUÇÃO}


INTRODUÇĀO

Os problemas nutricionais nos paises em desenvolvi mento tem sido estudados extensivamente. A saúde, de maneira ge ral, e o estado de nutrição de modo particular, são produtos de um quadro ecológico em que interagem os vários fatores do ambiente. Em outras palavras, os fatores próprios do hospedeiro, do ambiente $e$ do agente causal interferem conjuntamente na enferm dade clintica. - os fatores ambientais influem tanto sobre o agente como sobre o hospedeiro e desta maneira podem determinar a natureza e as consequências de ação recĩproca entre um e outro. Citamos, como exemplo, o caso particular de uma doença infecciosa. - a tuberculose. Como ela consiste em uma infecção provocada pelo bacilo de Koch, a enfermidade clinica poderá ter uma alta prevaléncia; no entanto, um nümero elevado de pessoas poderā estar infectado por este agente e somente pequena propor ção apresentarā a doença tuberculose. O desenvolvimento da doen ça depende (entre outras cousas) do contacto com o agente causal, do estado imunitário do indivíduo, e, em especial, do seu estado nutricional. - Os desnutridos tem maior probabilidade de 
contrair a doença, inclusive de forma mais grave, e atē mesmo vir à morrer.

0 mesmo pode se aplicar a uma doença carencial, em que outros fatores säo necessários além da carēncia de um nutrí ente para explicar a presença da deficiēncia em pauta. E o caso da anemia ferropría, que pode não ser devido apenas a uma caéncia de ferro na dieta. A doença pode se apresentar ou em pes sod com ingestăo de ferro insuficiente, ou com defeitos de absorçá, ou com perdas anormais de ferro, tendo como causas, enire outras, a ancilostomose, esquistosomose, metrorragia, ulcemis, $\in \mathrm{tc}$.

Os fatores ambientais, bem como o hospedeiro, podem fazer com que determinada ingestäo de nutriente especifico Ejis adequada ou deficiente.

Como vimos, os problemas nutric onais tem uma gêne se muit tijactoriai, envolvendo variávess, que nem sempre se encontram no campo operacional da saúde, interferindo, entre ouros elementos, os componentes sócio-económicos.

- Com relação à desnutrição proteico-energética, vemos que nos estudos hoje clássicos da Pan American Health organization (PAHO) sobre mortalidade infantilis, s9, em 13 regiões de 6 páses latino-americanos, de um total de 27.508 óbitos em meriores de um ano, $7.70 !(26,4 \%)$, tinham a subnutriçào como cau sa básica ou associada, chegando a $35,5 \%$ na cidade de Recife e 36,6\% em El Salvador; constatou-se ainda que das mortes perie neonatais, grande parte foi devida a imaturidade, dada princi- 
palmente a subnutrição materna. Em vista disto a Organização Mun día de Saúde (OMS) ${ }^{35}$, propõe como solução, a intẹgração interse torial nas politticas nacionais de saūde, com ènfase em alimentação e nutrição, como parte fundamental dos planos nacionais de desenvolvimento sócio-econōmico. Acreditamos que para haver esta integração é importante existir a participação da comunidade com os seguintes objetivos: a) obter um meihor conhecimento dela para facilitar a articulação dos sistemas institucionais e tradicionais comunitários de saúde; b) conhecer os conceitos que as populações rurałs e urbanas de baixo nĩvel sōcio-econōmico tem sobre saúde; c) obter um melhor conhecimento do interesse da popuiação por participar ativamente nos programas de saūde, assim como dos motivos pelos quais participaria $28,36,37,49$

Enquanto não se logra modificar os diversos fatores sócio-económicos que determinam a desnutrição, uma das estratēgias propostas é a suplementação alimentar ou a distribuição de alimentos para a proteção nutricional dos grupos vuineráveis : 19, 20. Esta suplementação alimentar deve ser fornecida ao grupo carente, porëm de forma imediata, a fim de que possa combater a desnutrição na sua forma aguda, sendo portanto, um plano emergen cralto, 4 . No planejamento de um programa de suplementação alimentar deve-se, na medida do possivel, prever a utilização de alimentos de produção local ou regional, com a participação atîva da comunidade, já que muitas vezes não se pode contar com a intervenção de programas internacionais de suplementação alimen$\tan 23,25,32,46,43$

Quando falamos que uma das estratégias propostas para modificar os diversos fatores sócio-econōmicos que determinam 
a desnutrição é a suplementação.alimentar, queremos dizer que, entre outros, este $e^{-}$um dos meios pelos quais podemos diminuir os elevados coeficientes de mortalidade e morbidade em crianças menopas de 5 anos: - No Nordeste brasileiro foi evidencia do um njomero elevado de öbitos pelas doenças carenciais, ou se ja, $46,2 \%$ somente em Recife ${ }^{3 s}$, ou-ainda porque analisando a inn terrelação entre deficiencia nutricional-e prematuridade, sentimos que estas são condiçöes que intervem no crescimento e de senvolvijento da criança, já que a prematuridade está associada ao bajxo peso ao nascer, indicando este-ültimo o crescimento e desenvolvimento intra-uterino deficientes e ainda um esta do carencial graye da mãe:o, ::,:2,:4,:3,2z, 2b, to

No modelo ecológico da desnutrição reịata-se que o fator básico é a baixa. renda per-capita da população. Tem sído destacado de releväncia a escolaridade da mãe como fator condicionante do estado nutricional do pré-escolar, principalmente no que diz respeito aos häbitos alimentares e conhecimen tos tradicjonais, $2,9,23,4: 45$

Ao reconhecer que os fatores condicionantes da desnutrição atuam simuịtaneamente em vários setores, é absolutamente necessärio realizar programas coordenados que assegurem a disponib:lidade e consumo adequado de alimentos e que por sua vez logrem a prevençăo, controle e tratamento daquelas doenças principalmente as transmissíveis agudas, que afetam adequada utịização biológica dos nutrientes. Por outro lado, a participação do setor saúde nos programas multisetoriais de alimentação e nutrição, implica sua responsabilidade em: diagnōstico e vigilância do estado nutricional e alimentar da popu 
lação; formulação de recomendações sobre. necessidades de nutrien tes e consumo alimentar; realização de programas especificos de prevenção, controle e recuperação de doenças carenciais e infecciosas; e necessária promoção e orientação dos planos para a prọ dução, distribuição e consumo de alimentos $67,13,16,22,25,32,46,47$.

Os fatores determinantes do estado nutricional, poderiam ser citados como: 1) a disponibilidade de alimentos para atender as necessidades da população; 2) o consumo suficiente e equilibrado de alimentos e 3 ) a utilização adequada dos alimentos por parte do organismo $0^{3246}$.

Devido a todos esses fatores, os governos federal e estaduais, através de diversos örgãos procuram implantar programas de suplementação alimentar, atendendo prioritariamente aos grupos vuinerāveis.

Em São Paulo, existem alguns desses programas, tais como:

- Merenda escolar, que visa o atendimento ao esco$\operatorname{lar}(7-14$ anos ), executado pela Secretaria da Educação.

- Programa de Nutrição ao Pré-Escolar (PRO-NUTRI), na rede da Secretaria de Promoção Social.

- Atividade de suplementação alimentar às gestantes, nutrizes e lactentes, nos centros de Saūde, órgäos executores da Secretaria de Saūde de são Pauto.

A população alvo da nossa pesquisa é beneficiada por 
uma atividade de suplementação. alimentar, provinda do Instituto Nacional de Alimentação e Nutrição-( INAN), em convēnio com a Secretaria de Saūde do Estado de São Paulo, que destinou um suplemento às prefeituras que pudessem executar o programa de saú de, onde o estímulo fosse o suplemento, distribuido às crianças de 1 a 6 anos de idade.

o suplemento distribuido é leite desriatado, com um per-capitamensal de um quilo e meio, cobrindo aproximadamente $76 \%$ das necessidades proteicas e $13 \%$ das necessidades calóricas do pré-escolar atendido.

A prefeitura de Carapicuiba se propós a melhorar o incremento calórico, oferecendo, junto ao leite desnatado, um quilo de fubà per-capita, ficando assim o pré-escolar com a cobertura de $87 \%$ em proteinas e $22 \%$ em calorias.

Tomando conhecimento desta atividade desenvolvida através da prefeitura de Carapicuiba, planejamos e executamos um estudo no sentido de conhecer a relação existente entre o estado nutricional de crianças de 1 a 4 anos de idade com suplementação alimentar, nĩvel sócio-econōmico e escolaridade da mãe. Ainda, pensamos estudar a interferéncia do nivel sócio-económico da familia e escolaridade da mãe, no estado nutricional de crianças de 1 a 4 anos de idade, beneficiäria da atividade suplementação alimentar. 
II - OBJETIVOS 
OBJETIVOS

1 - Estabelecer o diagnóstico da situação nutricio nal ao início da atividade de suplementação alimentar (linha de base).

2 - Caracterizar a população demandante quanto ao nĩvel sōcio-econōmico, bem como as suas relações com o estado nutricional dos pré-escolares pesquisados.

3 - Baseado nos objetivos 1 e 2 , planejar e execu tar atividades paralelas de educação nutricional e alimentar, utilizando o pessoal da Seção de Nutríção do Instituto de Saúde da Secretaria de Saúde do Estado de São Paulo.

4 - Avaliar num perīodo de 5 meses, as variāveis em estudo, principalmente as que dizem respeito ao nível sócioeconômico, educação alimentar e estado nutricional, bem como as suas modificações e interrelações. 


\section{I - CARACTERISTICA DA POPULAÇÃo}

ESTUDADA 
CARACTERISTICA DA POPULAÇÃO ESTUDADA

A população estudada foi em número de 240 pré-escó lares previamente amostrados.

Na Tabela 1, verificamos que os pais dos pré-escó lares estudados procederam do interior de São Paulo e outros es tados (pai $81,9 \%$ e mãe $67,0 \%$ ); de São Paulo-Capital a procedēncia dos pais era de $47,8 \%$ e somente $3,1 \%$ da região de Carapicuj ba.

Pelas características do município e os dados encontrados, supomos que a migração dos pais das crianças estudadas é recente, lamentando não termos levantado o tempo de resi dência no referido município. Consideramos este fato fundamental principalmente no que diz respeito a estabilidade de residéncia, hābitos e tabus alimentares.

A maioria dos pais das crianças estudadas possuem escolaridade primária e abaixo desta, enquanto que a parcela res BIBLIOTECA 
TABELA 1 - LUGAR DE PROCEDENCIA DOS PAIS DAS CRIANÇAS DE I A 4 ANOS DE IDADE, ESTUDADAS EM CARAPICUIBA, SÅO PAULO, 1979.

\begin{tabular}{|c|c|c|c|c|c|c|c|c|c|c|c|}
\hline \multicolumn{2}{|c|}{ PROCEDENCIA } & \multicolumn{2}{|c|}{ CARAPICUIBA } & \multirow{2}{*}{$\frac{S A O}{N^{8}}$} & \multirow{2}{*}{$\frac{\text { PAULO }}{\%}$} & \multirow{2}{*}{$\frac{\text { INTERIDR }}{N^{8}}$} & \multirow{2}{*}{$\frac{-S P}{\%}$} & \multicolumn{2}{|c|}{$\begin{array}{c}\text { OUTROS } \\
\text { ESTADOS } \\
\end{array}$} & \multicolumn{2}{|c|}{ TOTAL } \\
\hline PAIS & $N^{8} E \%$ & N? & $\%$ & & & & & $N^{8}$ & $\%$ & $N^{8}$ & $\%$ \\
\hline Pai & & 2 & 1,4 & 23 & 16,7 & 15 & 10,9 & 98 & 71,0 & 138 & 100,0 \\
\hline Mãe & & 4 & 1,7 & 73 & 31,1 & 24 & 10,2 & 134 & 57,0 & 235 & 100,0 \\
\hline TOTAL & & $B$ & 1,6 & 96 & 25,7 & 39 & 10,5 & 232 & 62,2 & 373 & 100,0 \\
\hline
\end{tabular}


tante (minoria), se encontra distribuida pelos outros níveis de escolaridade. de.maneira desigual. 
IV - MATERIAL E METODOS 
MATERIAL E METODOS

$$
\text { 1- Populacão (Universo) }
$$

Compreendeu os 6.528 prë-escolares de 1 a 6 anos de idade que frequentavam os postos de distribuição do leite des natado - INAN, no municipio de Carapicuiba em fevereiro de 1979.

Deste total 1.227 pré-escolares tinham idade com preendida entre 1 a 4 anos, sendo 613 do sexo masculino e 614 do sexo feminino.

Os postos de distribuição do leite eram em número de 13.

\section{2- Amostragem}

Do total de postos de distribuição, foram amostrados.4, atendendo a uma homogeneidade geogrāfica e sōcio-econō míca. 
A amostragem da popullação foi sistemática e alea tōria, compreendendo 240 crianças assim distribuidas segundo a idade:

1 a 2 anos -97 crianças
2 a 3 anos -107 crianças
3 a 4 anos -36 crianças

Quanto ao sexo 133 crianças eram do sexo masculi no e 107 do sexo feminino.

Estas crianças eram distribuidas nos postos da seguinte maneira: São Lucas - 80 crianças; Jardim Jussara - 80 crianças; Vila Crete - 40 crianças e Vila Santa Teresinha - 40 crianças.

\section{3- Questionārio}

Compreende 3 partes: levantamento sócio-econōmico, consumo alimentar e clīnico nutricional (ANEXO 1).

Do total de informações reunidas atravēs dos ques tionários, consideramos apenas: renda familiar, escolaridade da mãe, migração dos pais e antropometria - variáveis objeto da nossa. monografia.

3.1 Renda - foram estabelecidos sete niveis de renda a exemplo do trabalho de SINGER ${ }^{+5}$, utilizando como referēncia o salário minnimo (SM) da época (Cr\$1.560,00), dividido pela "famīlia padrão" ( 5 pessoas por familia): 
NIVEL

\begin{tabular}{|c|c|}
\hline 1 & 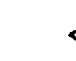 \\
\hline$?$ & 1 \\
\hline 3 & 2 \\
\hline 4 & 3 \\
\hline 5 & 4 \\
\hline & 5 \\
\hline 7 & $>d$ \\
\hline
\end{tabular}

$\operatorname{cr} \$$

SALARIO MTNIMO

$<$

312,00

312,00

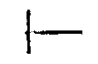

624,00

624,00

936,00

$936,00 \vdash 1.248,00$

$1.248,00$

$1.560,00$

$1.560,00$

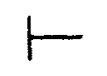

$1.872,00$

$\geq \quad 1.872,00$

Para a população em estudo a renda foi obtida pelo cómputo dos ingressos mensais da fa mîlia menos as despesas fixas com o pagamento da casa alugada ou prestação da casa própria; definindo esta como renda per-canita e classifi cada de acordo com os níveis referidos acima.

3.2 Escolaridade da mãe - foram estabelecidos sete nīveis:

1 - Sem escolaridade - Näo sabe ler ou apenas assina o nome, mas nunca esteve na escola.

2 - 19 Grau Incompleto - da 1a. à 7a. Sērie.

3 - lo Grau Completo - da la. à 8a. Sērie.

4 - 29 Grau Incompleto - da 1a: a 2a. Série.

5 - 29 Grau Completo - da la. à 3a. Série.

6 - Superior Incompleto.

7 - Superior Completo.

3.3 Migração - as famili ias foram classificadas segundo a procedéncia do pais, em quatro grupos: 
1. Carapicuiba

2. São Paulo - Capital

3. Interior de São Paulo

4. Outros estados.

3.4 Antropometria - foram coletadas em duas eta pas, informações sobre: pēso, estatura, perīmetro cefālico e perīmetro braquial. Tais medidas foram realizadas de acordo com a metodologia aconselhada por JELLIFE ${ }^{3}$. Para o pêso utilizou-se balança de alavanca, com sensibilidade de 100 gramas. A altura foi obtida em decúbito dorsal, usando antropometro horizontal. Para os perímetros cefálicos e braquial, foi utilizada fita métrica flexível e inelástica de meio centímetro de largura.

4- Critērios de Avaliação do-Estado Nutricional

No nosso estudo em particular como-critērio de avaliação do estado nutricional, optamos pela classificação de GOMEZ para os resultados finais, apresentação e discussão.

Esta opção foi feita em virtude de sabermos que a classificação de GOMEZ é satisfatorı auando feita pela compa ração dos valores ponderais encontraaos com as tabelas de refe rências aceitas como normas para determinada idade e determina do sexo ${ }^{17}$. Obtem-se assim, o nível de adequação entre o caso examinado e o padrão escolhido, classificando-se os resultados em "normais" ou "eutróficos" e desnutridos de I, II e II graus. 
De. modo.genérico, segundo. BATISTA $F Q^{5}$, na preva lência da desnutrição aferida pelo critério de GOMEZ, acham incluidos os casos atuais de crianças desnutridas ao lado dos casos que tiveram no seu passado, algum comprometimento irreversi vel no seu processo de crescimento, por razões nutricionais ou não. Este comprometimento reflete-se como efeito antropométrico, no atraso de crescimento estatural, atingindo assim, dimen são predominante nas medidas corporais. E a situação habitualmen te condicionada pelos processos crōnicos de desnutrição, sobre tudo quando atingindo crianças nos dois primeiros anos de vida.

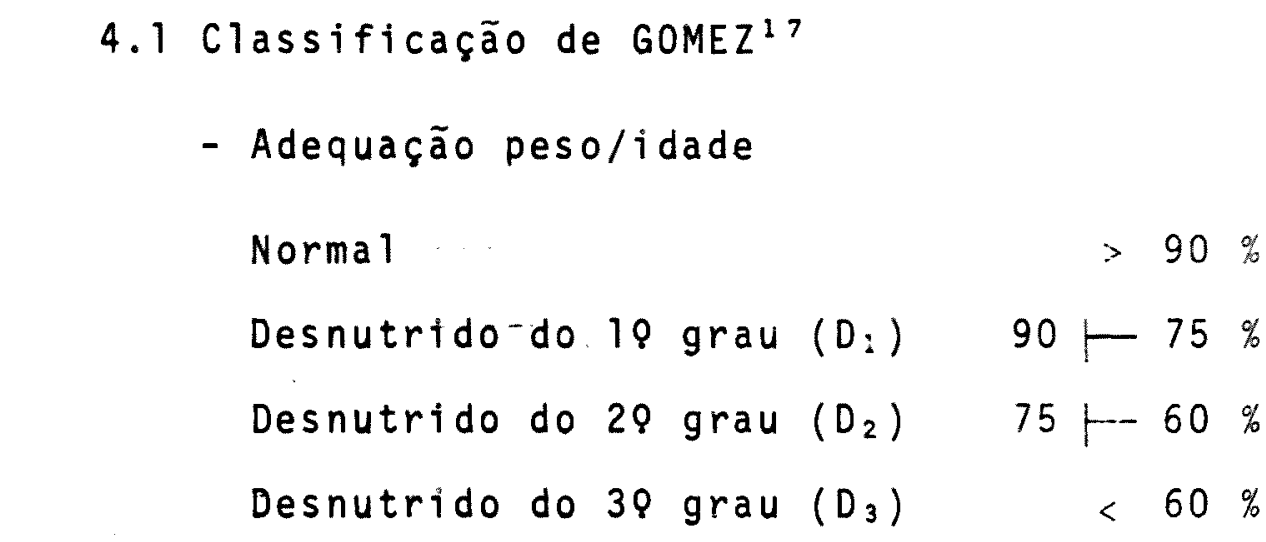

5- Exame Clïnico Nutricional

Foram pesquisados sinais clīnicos de desnutrição, segundo o esquema recomendado por JELLIFFE ${ }^{3}, \mathrm{OMS}^{35}$ e $\operatorname{MCLAREN}^{30}$. Pelas caracteristicas do estado nutricional de nossa população, optamos pela detecção de presença ou ausēncia de edema pré-tị bial.

Procedeu-se também no exame clīnico à procura de patologias aguda ou crọnica infecciosa, assim como quaisquer outras que interferissem no crescimento do pré-escolar. 


\section{6- Métoda Estatístico}

A anālise dos dados e o-interesse da pesquisa, en volveu frequentemente a comparação entre duas proporções. Estas diferenças foram testadas ao nivel de $5 \%$ ou menos com o objetivo de evidenciarmos os resultados"mais significativos.

\section{7 - Educação Alimentar.}

Atravēs do questionārio, procurou-se verificar o conhecimento das mães dos pré-escolares, sobre o valor nutritivo dos alimentos.

Durante 5 meses foram ministradas aulas de Educa ção Alimentar, onde os temas enfocados foram:

- Importāncia dos alimentos

- Funções dos alimentos

- Grupos de alimentos

- Preservação do valor nutritivo dos alimentos

- Grupos vuinerāveis à desnutrição

- Alimentação do pré-escolar

- Horta domiciliar e criação de animais de peque no porte.

Este programa foi ministrado por nutricionistas da seção de nutrição da Secretaria de Saūde do Estado de São Pau 10, jā que haviam planejado desenvolver um trabalho junto a este mesmo grupo etārio. 
V - RESUltAdOS: APRESENTAÇÃO E DISCUSSÃO 
RESULTADOS: APRESENTAÇAOO E DISCUSSÃO

1- Estado Nutricional - Sexo e Idade

GOMEZ et a $7^{18}$ e JELLIFFE ${ }^{3}$ tem demonstrado a al ta prevalēncia de desnutrição nesta faixa etária por nós estuda da.

Esta justificativa junto ao fato de maior crescimento e desenvolvimento de pré-escolar de 1 a 4 anos de idade nos levou a concentrar nosso estudo nesta faixa etāria, prenden do-nos ao fato de uma segunda avaliação cinco meses após, que nos permitiria avaliar com maior sensibilidade mudanças no esta do nutricional.

Foram examinadas 240 crianças de 1 a 4 anos de idade - 40,4\% de 1 a 2 anos - 44,5\% de 2 a 3 anos e $15,1 \%$ de 3 a 4 anos. (Tabela 2). 
TABELA 2 - DISTRIBUIÇÃO. DO NUMERO DE CRIANÇAS DE I A 4 ANOS DE IDADE, SEGUNDO O GRUPO ETARIO E ESTADO NUTRICJONAL (CLASSIFICAÇAO DE GOMEZ) - CARAPICUIBA, SÃO PAULO, FEVEREIRO DE 1979.

\begin{tabular}{|c|c|c|c|c|c|c|c|c|c|c|c|c|c|}
\hline \multicolumn{2}{|c|}{$\begin{array}{l}\text { ESTADO } \\
\text { NUTRICIONAL }\end{array}$} & \multicolumn{2}{|c|}{$\therefore$ TOTAL } & \multicolumn{2}{|c|}{ EUTROFICO } & \multicolumn{2}{|r|}{$D_{i}$} & \multicolumn{2}{|c|}{$\mathrm{D}_{2}$} & \multicolumn{2}{|c|}{$D_{3}$} & \multicolumn{2}{|c|}{$\begin{array}{c}\text { TOTAL } \\
\text { DESNUTRIDO } \\
\end{array}$} \\
\hline GRUPO & ETARIO & $N^{8}$ & $\%$ & $N^{8}$ & $\because$ & $N^{8}$ & $\because$ & $N^{8}$ & $\%$ & $N^{9}$ & $\%$ & $N^{8}$ & $\%$ \\
\hline $1 \vdash$ & 2 & 97 & 100,0 & 64 & 66,0 & 28 & 29,0 & 4 & 4,1 & 1 & 1,0 & 33 & 34,1 \\
\hline $2 \longmapsto$ & 3 & 107 & 100,0 & 65 & 60,8 & 32 & 29,9 & 9 & 8,4 & 1 & 0.9 & 42 & 39,2 \\
\hline $3 H$ & 4 & 36 & 100,0 & 22 & 61,1 & 14 & 38,9 & - & - & - & - & 14 & 38,9 \\
\hline TOTAL & & 240 & 100,0 & 151 & 62,9 & 74 & 30,8 & 13 & 5,5 & 2 & 0,8 & 89 & 37.1 \\
\hline
\end{tabular}


Encontrou-se que $37,1 \%$ desta população tinha al gum grau de desnutrição, segundo a classificação de GOMEZ ${ }^{17}$ : sen do que $30,8 \%$ correspondiam ao primeiro grau de desnutrição, 5,5\% ao segundo grau e $0,8 \%$ ao terceiro grau. Estes dados concordam com os resultados de outros autores... Segundo. ARIZA MACIAS ${ }^{1}$, BATISTA F ${ }^{5}$ e YUNES ${ }^{3}$, a desnutrição ocorre mais frequentemente com menos de 3 anos, e IUNES et a $1^{21}$, ocorre em crianças de até 60 meses. Como nossa população é constituida por crianças até 4 anos. de idade, $84,9 \%$ das quais atē 3 anos; acreditamos que os resultados por nós encontrados estão de acordo com os dos a $\underline{u}$ tores citados.

Distribuindo-se os resultados, segundo idade, verificamos que as proporções de desnutridos nos trēs grupos etā rios se equivalem, entretanto no grupo de 3 a 4 anos não encontramos desnutrição graus dois e trēs $\left(D_{2}, D_{3}\right)$, e nos demais gru pos pequena proporção de ambos os graus.

Na Tabela 3 , que se refere a 120 das crianças da Tabela 2 examinadas 5 meses depois, distribuidas tambēm segundo idade, verificamos que a proporção de crianças eutróficas aumen tou. nos trēs grupos, porém, as diferenças não foram estatiscamen te significantes. Cumpre ainda notar que nos grupos etários de 1 a. 2 e 2 a 3 anos, havia ainda uma criança com desnutrição grau trēs $\left(D_{3}\right)$ em cada grupo; mas, não encontramos crianças com desnutrição grau dois $\left(D_{2}\right)$.

A Tabela 4 mostra as crianças examinadas na prị meira fase distribuidas segundo o sexo. Nota-se que as proporções referentes às crianças eutrófica com desnutrição um $\left(D_{1}\right)$ 
TABELA 3 - DISTRIBUIÇÃO DO NUMERO DE CRIANÇAS DE I A 4 ANDS DE IDADE, SEGUNDO D GRUPD ETARIO E EStAdO NUTRICIONAL (CLASSificAÇÃO DE GUMEZ) - CARAPICUIBA, SÃO PAULO, JULHO DE 1979.

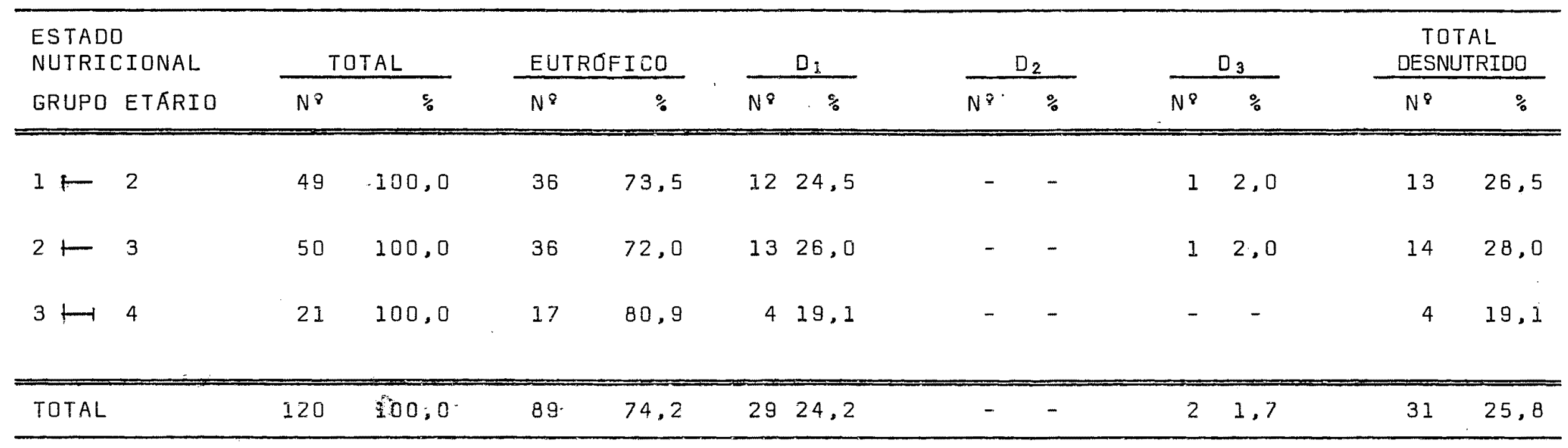


TABELA 4 - DISTRIBUIÇAO DO NÜMERO dE CRIANÇAS DE I A 4 ANOS DE IDADE, SEGUNDO O SEXD E ESTADD NUTRICIONAL (CLASSIFICAÇÃO DE GOMEZ) - CARAPICUIBA, SAOO PAULO, FEVEREIRO DE 1979.

\begin{tabular}{|c|c|c|c|c|c|c|c|c|c|c|c|c|}
\hline \multirow{2}{*}{$\begin{array}{l}\text { ESTADO } \\
\text { NUTRICIONAL } \\
\text { SEXO }\end{array}$} & \multicolumn{2}{|c|}{ TOTAL } & \multicolumn{2}{|c|}{ EUTROFICO } & \multicolumn{2}{|r|}{$D_{1}$} & \multicolumn{2}{|c|}{$D_{2}$} & \multicolumn{2}{|c|}{$D_{3}$} & \multicolumn{2}{|c|}{$\begin{array}{c}\text { TOTAL } \\
\text { DESNUTRIDD } \\
\end{array}$} \\
\hline & $N^{8}$ & $\%$ & $N^{8}$ & $\because$ & $N^{8}$ & $\%$ & $N^{8}$ & $\%$ & $N^{8}$ & $\%$ & $N^{\circ}$ & $\%$ \\
\hline Masculino & 133 & 100,0 & 83 & 62,4 & 39 & 29,3 & 10 & 7,5 & 1 & 0,8 & 50 & 37.5 \\
\hline Feminino & 107 & 100,0 & 68 & 63,6 & 35 & 32,7 & 3 & 2,8 & 1 & 0,9 & 39 & 36,4 \\
\hline TOTAL & 240 & 100,0 & 151 & 62,9 & 74 & 30,8 & 13 & 5,4 & 2 & 0,8 & 89 & 37,1 \\
\hline
\end{tabular}


e desnutricão trēs $\left(D_{3}\right)$ se equivalem, porém, nas do sexo masculino, vamos encontrar uma proporção bem mais elevada do que a das do sexo feminino. Entretanto esta diferença não foi estatis ticamente significante.

Destas 240 crianças, 120 foram re-examinadas cin co meses mais tarde (Tabela 5).

Na Tabela 5, verificamos que houve um aumento nas proporções correspondentes às crianças eutróficas e uma diminui ção naquelas correspondente a desnutrição um $\left(D_{1}\right)$. Não encontramos crianças com desnutrição dois $\left(D_{2}\right)$, mas, as duas crianças, uma do sexo masculino e outra do sexo feminino que apresentaram desnutrição trēs $\left(D_{3}\right)$ na primeira etapa, continuaram apresentan do. o. mesmo-grau. de desnutrição.

As diferenças encontradas-nas duas.etapas não foram significantes estatisticamente.

\section{2- Escolaridade da Mãe e Estado Nutricional}

Sabemos que principalmente em nutrição, a educa ção é o-processo essencial, para transmitir o conhecimento cien tîfico que hā de aplicar o individuo. Não obstante, a facilidade com que este possa educar-se depende em grande medida do grau de alfabetização. O analfabetismo e a baixa escolaridade não só representa uma barreira para os meios contemporāneos de comunicação, mas também, ajuda a perpetuar conhecimentos tradicionais, muitos-dos quais prejudicam ao individuo e a comunidade. 
TABELA 5 - DISTRIBUIÇÃO DO NUMERO dE CRIANÇAS DE I A 4 ANOS DE IDADE, SEGUNDO. O SEXO E ESTADO NUTRICIONAL (CLASSIFICAÇÃO DE SOMEZ) - CARAPICUIBA, SAO PAULO, JULHO DE 1979.

\begin{tabular}{|c|c|c|c|c|c|c|c|c|c|c|c|c|}
\hline \multirow{2}{*}{$\begin{array}{l}\text { ESTADO } \\
\text { NUTRICIONAL } \\
\text { SEXO }\end{array}$} & \multicolumn{2}{|c|}{ TOTAL } & \multicolumn{2}{|c|}{ EUTROFICO } & \multicolumn{2}{|r|}{$D_{2}$} & \multicolumn{2}{|c|}{$\mathrm{D}_{2}$} & \multicolumn{2}{|c|}{$D_{3}$} & \multicolumn{2}{|c|}{$\begin{array}{c}\text { TOTAL } \\
\text { DESNUTRIDO } \\
\end{array}$} \\
\hline & $N^{8}$ & $\%$ & $N^{8}$ & $\%$ & $N^{2}$ & $\%$ & $N^{8}$ & $\%$ & $N^{8}$ & $\%$ & $N^{8}$ & $\%$ \\
\hline Masculino & 65 & 100,0 & 48 & 73,9 & 16 & 24,6 & - & - & $I$ & 1.5 & 17 & 26,1 \\
\hline Feminino & 55 & 100,0 & 41 & 74,6 & 13 & 23,6 & - & - & 2 & 1.8 & 14 & 25,4 \\
\hline TOTAL & 120 & 100,0 & 89 & 74,2 & 29 & 24,2 & - & - & 2 & 1,7 & 31 & 25,8 \\
\hline
\end{tabular}


Esta característica. não só é importante para a operacionalidade de qualquer atividade educativa nesta população, mas tambēm como variável condicionante do estado nutricio nal do pré-escolar.

Na população estudada, verificamos que de um total de 240 crianças haviam 53 cujas mães não tinham escolari dade e 164 cujas mães tinham primeiro grau incompleto; vê-se portanto que as mães de 217 crianças tinham no mäximo, primeiro grău incompleto o que corresponde a $90,4 \%$.

Pela inspecção na Tabela 6 , podemos ver que $47,2 \%$ das crianças, cujas mães não tinham escolaridade eram des nutridas (a-maior parte - $35,8 \%$ - desnutridas do primeiro grau $\left(D_{1}\right)$; a frequência da desnutrição do terceiro grau $\left(D_{3}\right)$ foi nula). Com reiação-às crianças cujas mães-tinham primeiro grau incompleto, $35,4 \%$ eram desnutridas (a maioria - 30,5\% - do pri meiro grau $\left(D_{1}\right)$, aparecendo neste grupo $1,2 \%$ de crianças com desnutrição do terceiro grau $\left(D_{3}\right)$ ). Estes dados estão de acor do com a nossa expectativa ao iniciarmos o trabalho.

Nos demais grupos verificamos que $25 \%$ das crianças cujas mães tinham o primeiro grau completo e $28,5 \%$ da quelas cujas mães tinham o segundo grau. incompleto eram desnu tridas.

Embora a-diferença seja pequena era de se espe rar. uma..proporção-menor no ūitiomo grupo. (mãe com_.segundo grau incompleto). Entretanto devemos ter em mente que os números dos $\bar{u} 1$ timos dois grupos são pouco consistentes (16 e 7 respectivamente). 
TABELA 6 - DISTRIBUIÇÃO DO NUMERO DE CRIANÇAS DE I A 4 ANOS DE IDADE, SEGUNDO. ESCDLARIDADE DA MÃE E ESTADO NUTRICIONAL (CLASSIFICAÇÃO DE GOMEZ) - CARAPICUIBA, SÃO PAULO, FEVEREIRO DE 1979 .

\begin{tabular}{|c|c|c|c|c|c|c|c|c|c|c|c|c|}
\hline \multirow{2}{*}{$\begin{array}{l}\text { ESTADO } \\
\text { NUTRICIONAL } \\
\text { ESCOLARIDADE } \\
\text { DA MÃE }\end{array}$} & \multicolumn{2}{|c|}{ TOTAL } & \multicolumn{2}{|c|}{ EUTROFF ICO } & \multicolumn{2}{|r|}{$D_{1}$} & \multicolumn{2}{|r|}{$\mathrm{D}_{2}$} & \multicolumn{2}{|c|}{$\mathrm{D}_{3}$} & \multicolumn{2}{|c|}{$\begin{array}{c}\text { TOTAL } \\
\text { DESNUTRIDO }\end{array}$} \\
\hline & $N^{8}$ & $\%$ & $N^{8}$ & $\%$ & $N^{8}$ & $\%$ & $N^{8}$ & $\%$ & $N^{8}$ & $\%$ & $N^{8}$ & $\%$ \\
\hline Sem Escolaridade & 53 & 100,0 & 28 & 52,8 & 19 & 35,8 & 6 & 11,3 & - & - & 25 & 47.2 \\
\hline $1^{8}$ Grau Incompleto & 164 & 100,0 & 106 & 64,6 & 50 & 30,5 & 6 & 3,7 & 2 & 1,2 & 58 & 35,4 \\
\hline $1^{8}$ Grau Completo & 16 & 100,0 & 12 & 75,0 & 3 & 18,8 & 1 & 6,3 & - & - & 4 & 25,0 \\
\hline $2^{8} \mathrm{Grau}$ Incompleto & 7 & 100,0 & 5 & 71,5 & 2 & 14,3 & - & - & - & - & 2 & 28,5 \\
\hline TOTAL & 240 & 100,0 & 151 & 62,9 & 74 & 30,8 & 13 & 5,4 & 2 & 0,8 & 89 & 37,1 \\
\hline
\end{tabular}


$\mathrm{Na} 2 \mathrm{a}$. fase foram examinadas apenas 120 crianças, das quais $89,2 \%$ tinham mães sem escolaridade e primeiro grau incompleto.

Examinando a Tabela 7, verificamos que haviam apenas $22,2 \%$ de crianças desnutridas (todas do primeiro grau). No grupo primeiro grau incompleto encontramos $27.4 \%$ de crianças desnutridas. ( 15 das quais $-24,2 \%$ do primeiro grau $\left(D_{1}\right)$ e 2 do segundo.grau $\left(D_{2}\right)$ ). Nos demais grupos encontramos $33,3 \%$ para primeiro grau incompleto e $25,0 \%$ segundo grau incompleto de crianças desnutridas. Entretanto, os números para estes dois grupos-são mais uma vez, pouco consistentes.

A redução para o grupo sem escolaridade foi acentuado. $(25,0 \%)$, e altamente significante $(p=0,0094)$. Para 0 grupo.primeiro grau incompleto a redução foi apenas de $8,0 \%$ que não se mostrou significante ao nivel de $5 \%$. Estes resultados nos causaram surpresa, pois "a educação é o processo essencial para se transmitir conhecimentos", e, as mães menos privilegia das foram as que mostraram melhor aproveitamento do processo educativo a que foram submetidas.

3- Renda e Estado Nutricional

E aceito que o fator condicionante do estado nutricional.ē a distribuição de renda. Segundo os dados do Ins tituto de Pesquisa Econōmica da Universidade de São Paulo SIN GER ${ }^{45}$, a renda crītica está entre 0,5 a 1 salārio mīnimo percapita. Este parāmetro definiria o ponto crítico abaixo do qual aumenta a prevaléncia dos problemas nutricionais. Igualmente 
TABELA 7 - DISTRIBUiÇÃO DO NUMERO DE CRIANÇAS DE 1 A 4 ANOS DE IDAdE, SEGUNDO ESCOLARIDADE DA MÄE E ESTADO NUTRICIONAL (CLASSIFICAÇÃ DE GOMEZ) - CARAPICUIBA, SÃo PAULO, JULHO DE 1979.

\begin{tabular}{|c|c|c|c|c|c|c|c|c|c|c|c|c|}
\hline \multirow{2}{*}{$\begin{array}{l}\text { ESTADO } \\
\text { NUTRICIONAL } \\
\text { ESCOLARIDADE } \\
\text { DA MAE }\end{array}$} & \multicolumn{2}{|c|}{ TOTAL } & \multicolumn{2}{|c|}{ EUTROFICD } & \multicolumn{2}{|r|}{$D_{1}$} & \multicolumn{2}{|c|}{$\mathrm{D}_{2}$} & \multicolumn{2}{|c|}{$D_{3}$} & \multicolumn{2}{|c|}{$\begin{array}{c}\text { TOTAL } \\
\text { DESNUTRIDO } \\
\end{array}$} \\
\hline & $N^{8}$ & $\%$ & $N^{2}$ & $\%$ & $N^{8}$ & $\%$ & $n^{8}$ & $\%$ & $N^{8}$ & $\%$ & $N^{8}$ & $\%$ \\
\hline Sem Escolaridade & 45 & 100,0 & 35 & 77.8 & 10 & 22,2 & - & - & - & - & 10 & 22,2 \\
\hline $1^{9}$ Grau Incompleto & 62 & 100,0 & 45 & 72,6 & 15 & 24,2 & - & - & 2 & 3,2 & 17 & 27,4 \\
\hline $1^{8}$ Grau Completo & 9 & 100,0 & 6 & 66,7 & 3 & 33,3 & - & - & - & - & 3 & 33,3 \\
\hline $2^{8}$ Grau Incompleto & 4 & 100,0 & 3 & 75,0 & 1 & 25,0 & - & - & - & - & 1 & 25,0 \\
\hline TOTAL & 120 & $100 ; 0$ & 89 & 74,2 & 29 & 24,2 & - & - & 2 & 1,7 & 31 & 25,8 \\
\hline
\end{tabular}


ZACCI $^{54}$, constatou. esta. cifra.em 1 salärio mínimo na Fundação de Assistência a Infāncia de Santo André (FAISA), São Paulo.

IUNES ${ }^{2} 1$ comprovou a associação entre renda e des nutrição em crianças de seis meses a cinco anos de. 1 dade no mun cípio de São Paulo, encontrando uma alta prevaléncia de desnutri dos abaixo de um e meio $\left(1 / \frac{1}{2}\right)$ salärios minimos.

Em nosso estudo encontramos 40 crianças $(16,7 \%)$ cuja renda per-capita era inferior a 1 salário mínimo. $89(37,1 \%)$ de 1 a 2 salärios miñimos que corresponde a 129 crianças $(53,8 \%)$, com uma renda per-capita inferior a 2 salärios mínimos, dados que se aproximam aos publicados por SINGER ${ }^{4}$.

Com relação ao estado nutricional relacionado a renda per-capita podemos ver pela Tabela 8..que: quanto menor a renda maior a proporção de desnutridos.

Como os nūmeros nas categorias de renda de 3 a mais salärios mīnimos, são poucos consistentes reunimo-los em um ünico grupo.

Comparando as proporções do grupo de menos de 1 salário mínimo, de 1 a 2 salārios mīnimos e de 2 a 3 , verificamos que as diferenças não são significantes. Entretanto, comparando estes grupos menos de 1 salärio minimo versus 3 e mais $(<1$ S.M. X $3 \mathrm{e}+)$, verificamos què a diferença è altamente sig nificante $(P=0,004)$. O mesmo acontecendo quando comparamos os grupos 1 a 2 salārios minnimos versus 3 e mais ( 1 a 2 S.M. X 3 e +), $p=0,002$ e os grupos 2 a 3 salários mīnimos versus 3 e mais ( 2 a 3 S.M. X 3 e +), $p=0,008$. 
Na segunda fase do nosso estudo, examinamos tam bém 120 crianças e encontramos 22 crianças $(18,3 \%)$ no grupo de menos de 1 salārio mīnimo; 46 (38,3\%), no grupo de 1 a 2 salários minnimos, perfazendo um total de 68 crianças $(56,6 \%)$ com renda per-capita inferior a. 2 salārios mīnimose (Tabela 9).

Reunimos os grupos.de 3 salārios mīnimos e mais em um único grupo pelas mesmas razões pelas quais o fizemos na primeira fase.

A inspeção das. Tabelas.8.e. 9 , permite ver que há uma redução das proporções de desnutridos dos dois primeiros grupos, um aumento nos grupos de 2 a 3 salärios mínimos e nos grupos de 3 e mais salários mínimos, as proporções permaneceram constantes.

0. grupo.de-1. a 2 salārios mīnimos foi.o que apre sentou a maior redução (de $40,5 \%$ para $23,9 \%$ ). Esta foi a única redução significante a um nível de $5 \%$. Estes fatos sugerem que apenas este grupo auferiu benefícios do programa educativo implementado.

Os dados das Tabelas 8 e 9 , podem ser melhores apreciados no Gräfico a.

\section{4- Clīnico Nutricional}

Devido a dificuldade operacional de sinais clínicos de carēncia nutricional, segundo classificação de JELLIFFE ${ }^{3}$, nós optamos por concentrar nossa atenção na procura de edema 
TABELA 8 - DISTRIBUIÇÃO DO NUMERO DE CRIANÇAS DE I A 4 ANOS DE IDADE, SEGUNDO O ESTADO NUTRICIONAL (CLASSIFICAÇÃo DE GOMEZ) E RENDA PER-CAPITA, CARAPICUIBA, SÃo PAULO, FEVEREIRODE 1979.

\begin{tabular}{|c|c|c|c|c|c|c|c|c|c|c|c|c|}
\hline \multirow{2}{*}{$\begin{array}{l}\text { ESTADO } \\
\text { NUTRICIONAL } \\
\text { RENDA } \\
\text { PER-CAPITA } \\
\end{array}$} & \multicolumn{2}{|c|}{ TOTAL } & \multicolumn{2}{|c|}{ EUTRÓFICO } & \multicolumn{2}{|r|}{$D_{1}$} & \multicolumn{2}{|r|}{$\mathrm{D}_{2}$} & \multicolumn{2}{|c|}{$D_{3}$} & \multicolumn{2}{|c|}{$\begin{array}{c}\text { TOTAL } \\
\text { DESNUTRIDO }\end{array}$} \\
\hline & $N^{8}$ & $\%$ & $N^{8}$ & $\%$ & $N^{8}$ & $\%$ & $N^{8}$ & . \% & $N^{8}$ & $\%$ & $N^{8}$ & $\%$ \\
\hline$<1$ S.M. & 40 & 100,0 & 23 & 57,5 & 14 & 35,4 & 3 & 7,5 & - & - & 17 & 42,5 \\
\hline $1 \longmapsto 2$ S.M. & 89 & 100,0 & 53 & 59,5 & 31 & 34,8 & 4 & 4,5 & 1 & 1,2 & 36 & 40,5 \\
\hline $2 \longmapsto 3$ S.M. & 59 & 100,0 & 37 & 62,7 & 18 & 30,5 & 3 & 5,1 & 1 & 2.7 & 22 & 37,3 \\
\hline $3 e+S . M$. & 52 & 100,0 & 41 & 78,8 & 9 & 17,3 & 2 & 3,8 & - & - & 11 & 21,2 \\
\hline TOTAL & 240 & 100,0 & 154 & 64,1 & 72 & 30,0 & 12 & 5,1 & 2 & 0.8 & 86 & 35,9 \\
\hline
\end{tabular}


TABELA 9 - DISTRIBUIÇÃO DO NUMERO DE CRIANÇAS DE 1 A 4 ANOS DE IDADE, SEGUNDO O ESTADO NUTRICIONAL (CLASSIFICAÇÃO DE GOMEZ) E RENDA PER-CAPITA, CARAPICUIBA, SÃO PAULO, JULHO DE 1979 .

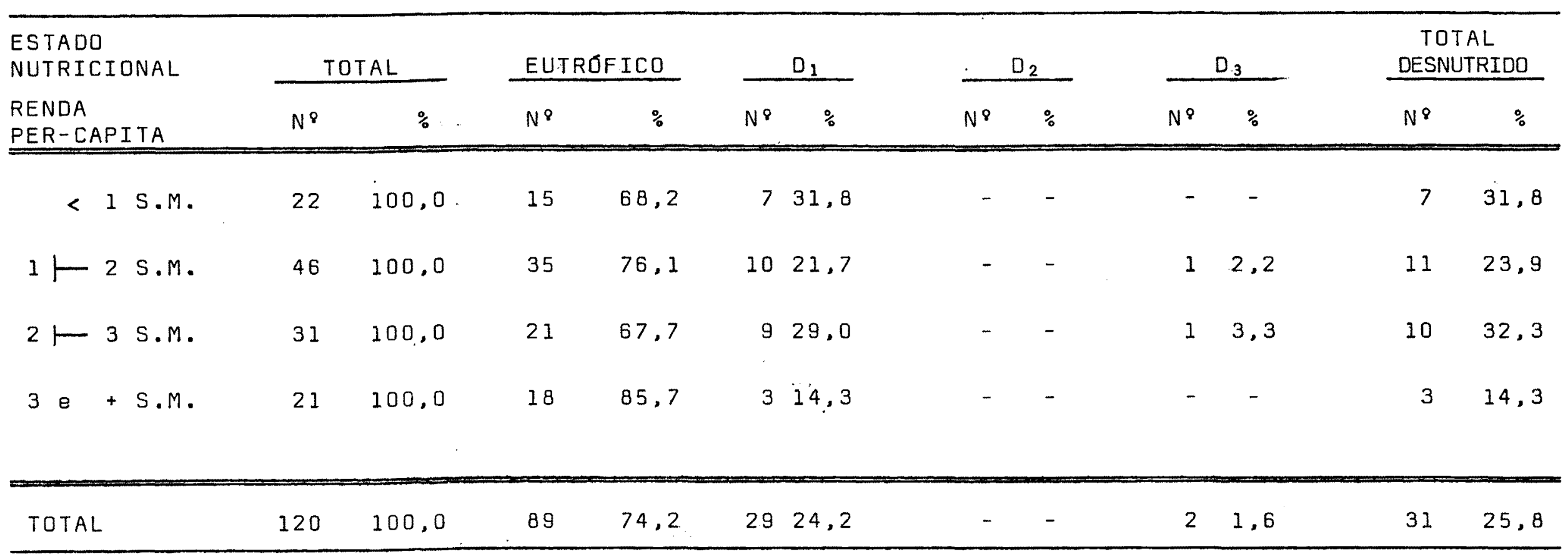




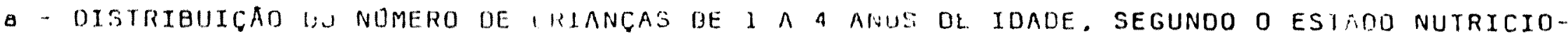
NAL (CLASSIFICAÇAO dE GOMEZ) E RENDA PER-CAPTIA. CARAPICUIGA. SAO PAULO. 1979.

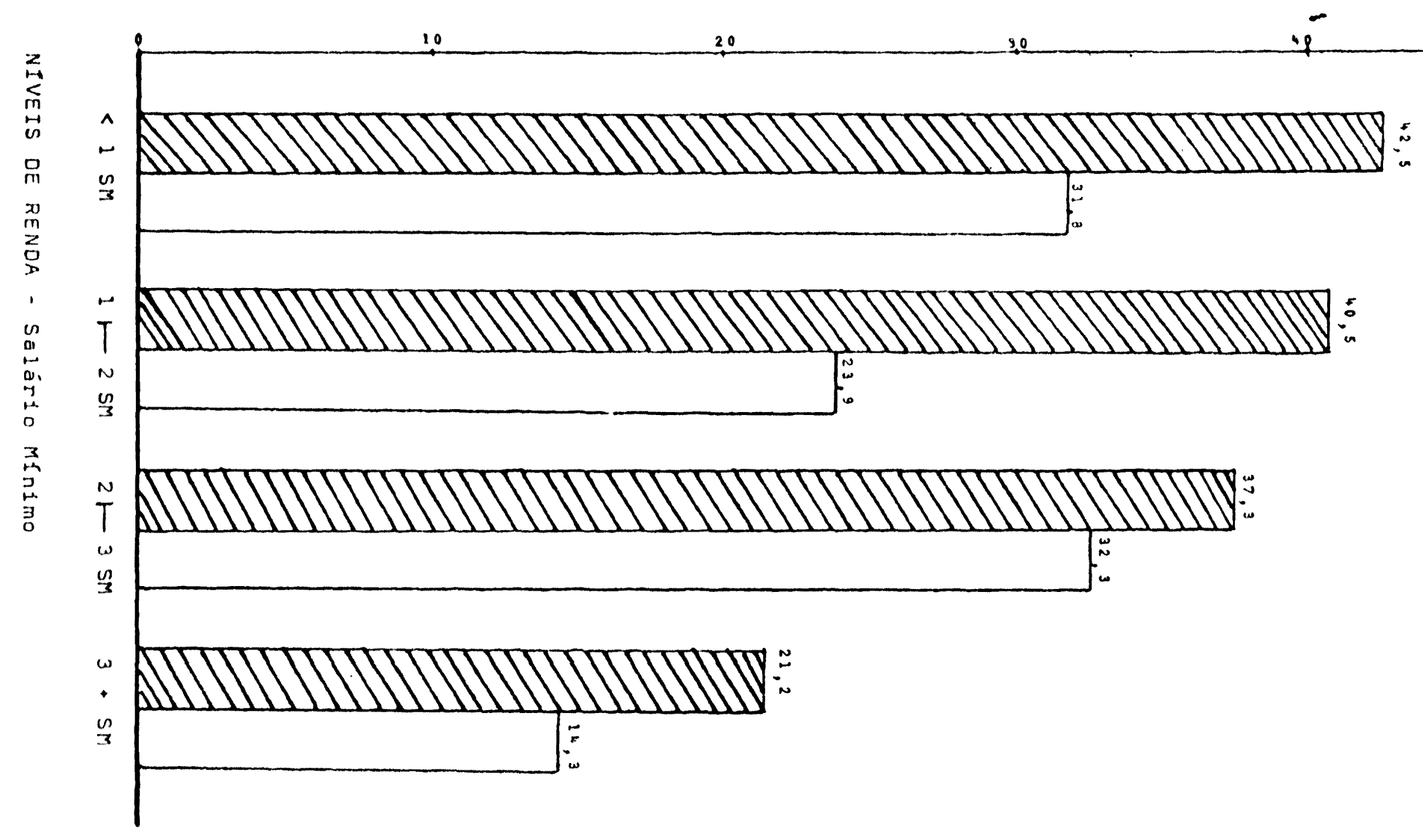


pré-tibial, que caracterizaria o terceiro grau de desnutrição de GOMEZ. Dois casos apresentaram desnutrição proteico-energé tica de terceiro grau misto (marasmático com edema), sendo que pela adequação peso/idade correspondiam a eutrófico e des nutrição do segundo grau $\left(D_{2}\right)$. 
VI - CONCLUSOES 


\section{CONCLUSOES}

1- A frequēncia de crianças de 1 a 4 anos de idade, comalgum grau de desnutrição, segundo a..classificação de GOMEZ, foi de $37,1 \%$ na primeira fase e de $25,8 \%$ na segunda.

2- Verificamos que na. segunda fase houve uma diminuição..nas proporções correspondentes às crianças desnutridas do -primeiro grau $\left(D_{1}\right)$.

3- Na segunda fase não encontramos crianças com des nutrição grau dois $\left(D_{2}\right)$, porém as duas crianças, uma do sexo mas culino e outra do sexo feminino que apresentaram desnutrição $\left(D_{3}\right)$ na-primeira fase, continuaram apresentando o mesmo grau de desnu trição. na segunda.

4-Verificamos que $90,4 \%$ das mães de 217 prē-escola res, não tinham escolaridade ou apresentavam primeiro grau incom pleto na-primeira fase e $89,2 \%$ na segunda. 
5- Na segunda fase a redução de crianças desnutridas para o grupo de mães sem escolaridade foi acentuada e altamente significante.

6- Notamos que as mães menos privilegiadas (sem es colaridade e primeiro grau incompleto), foram as que aparentemen te mostraram melhor aproveitamento do processo educativo a que foram submetidas.

7- 53,8\% da população estudada tinha renda per-capita inferior a dois salärios minimos na primeira fase e $56,6 \%$ na segunda.

8- As proporções de crianças desnutridas, correspondentes aos grupos de renda "per-capita" inferior a dois sala rios minnimos (2 S.M.) foram as que apresentaram maior redução, principalmente o grupo menor de um salārio minnimo ( 1 S.M.).

9 - Do ponto de vista da operacionalidade da atividade da suplementação alimentar e da educação nutricional, o presente trabalho contribuiu ao diagnóstico inicial do estado nutricional dos pré-escolares objetos do estudo. 
VII - REFERENCIAS BIBLIOGRAFICAS 
REFERENCIA BIBLIOGRAFICA

1. ARIZA MACIAS, J. - Metodo para la evaluaciōn del crecimen to de hombre y mujeres desde el nacimiento haste los 20 años, para uso de nivel nacional y internacional. Arch.lat.amer.Nutr., 22 (4): 533-546, 1972.

2. ASTURIAS, C.B. - La planificaciōn de la educaciōn nutricional en programas escolares. Bol. ofic.sanit,panamer., $\underline{65}(3): 187-195,1968$.

3. BACKHEUSER, M.P. et a 1. - Um programa de educação comunitāria para a saūde. Bol.ofic.sanit.panamer., 84 (3): $255-261,1978$.

4. BAEZ, M.C. - Enfermeria y nutriciōn en los servicios de salud. Bol.ofic.sanit.panamer., 81 (5): 398, 1976 .

5. BATISTA Fọ, M. - Prevalência e estāgios da desnutrição pro teico - calōrica em crianças da cidade de são paulo. 
São Paulo, 1976 (Tese Doutoramento, Faculdade de Saūde Pública da USP).

6. BEGHIN, I.D. - Estado presente y futuro de la nutrición humana en el istmo centroamericano..Rev.Biol.Trop., 24 (sup 1.): 13-23, 1976 .

7. BEHAR, M. - Evaluación de la situación nutricional en grupos de poblaciōn. Arch.lat.amer.Nutr., 22 (1): 335356,1972 .

8. BEHAR, M: - La responsabilidad del sector salud en la alimentaciōn y nutriciōn. Bol.ofic.sanit.panamer., 75 (5) : $395-405,1973$.

9. BURGUESS, A. et al. - Nutrition education in public health programs. What have we 1earned? Amer.publ.Hlth. 51: $1515-1726,1961$.

10. CHAVES, N. - A influência da nutrição e outros fatores do ambiente no desenvolvimento da criança. Med.Hoje, I (8): $20-27,1975$.

11. CHAVES, N. - Nutrição, desenvolvimento e crescimento. In - Nutrição bāsica e aplicada, Rio de Janeiro, Guanabara Koogan, 1978. p. 178-186.

12. COELHO, H.A.L. - Nutrição dos grupos etārios. In CHAVES, N. - Nutrição básica e aplicada. Rio de Janeiro, Guanabara Koogan, 1978. p. 161-170. 
13. COMITE MIXTO FAO/OMS DE EXPERTOS EN NUTRICION, 99, ROMa, 1974.-Estratégias alimentarias y nutricionales en el desarrollo nacional, informe. Ginebra, 1976 (OMS-Ser. inf.tecn., 584).

14. Coutinho, E.M. - Nutrição e saūde publica. Nutrição $x$ infecções. In CHAVES, N. - Nutrição bāsica e aplicada. Rio de Janeiro, Guanabara Koogan, 1978. 1978, p. $233-240$.

15. CRAVIOTO, J. \& De LICARDIE, E.R. - La malnutriciōn preços en 1a 1a. infancia. Alim.Nutr., 2 (4): 2-12, 1976.

16. GANDRA, Y.R. \& SCRIMSHAW, N.S. - Infection and nutrition status. II Effect of mild virus infection induced by 17 - D Yellow fever vaccine on nitrogen metabolism in children. Amer.J.clin.Nut., g (2): 159-163, 1961.

17. GOMEZ, F. - Desnutriciōn. Bol.med.Hosp.infant., $\underline{3}$ (4): $543-551,1976$.

18. GOMEZ, F. et al. - Mortality in second and third degree malnutrition. J.Trop.Pediat., 2 (2): 77-83, 1956.

19. INSTITUTO DE NUTRICION DE CENTRO AMERICA Y PANAMA. Divisiōn de Desarrollo Humano. Nutriciōn, crecimiento y desarro110. Bol.Ofic.sanit.panamer., 78 (1): 38-51, 1975 . 
nacional de alimentação e nutrição. PRONAN: 1976 1979. Brasilia, 1976 (Doc. tecn., INAN - 06/76).

21. IUNES, M. et a1. - Estado nutricional de crianças de 6 a 60 meses no município de são Paulo. II Anālise de dados. São Paulo, Escola Paulista de Medicina. Departamento de Medicina Preventiva, 1975.

22. JAMES, J.W. - Longitudinal study of the morbidity of diarrheal and respiratory infection in malnourished children. Amer.J.clin.Nutr, 25 (7): 690-694, 1972.

23. JELLIFFE, D.B. - Evaluación del estado de nutrición de la comunidad lcom especial referencia a las encuestas en las regiones en desarrollol. Ginebra, organización Mundial de la Salud, 1958 (OMS - Ser.monografias, 53).

24. KANAWATI, A.A.\& MCLAREN, D.S. - Assement of marginal ma1nutrition. Nature, 228 (5271): 573-575, 1970 .

25. KEVANY, J.P. - Problemas de nutriciōn del niño preescolar en America Latina. Bol.ofic.sanit.panamer., 60 $282-292,1966$.

26. KLEIN, R.E。 et a1. - Efectos de la nutrición materna sobre el crecimiento fetal y el desarrollo del ninõ. Bol.ofic.sanit.panamer., 83 (1):66-72, 1977 .

27. LOWY, G. \& MEILMAN, I. - Desnutrición calorico-proteico. Rev.med.Est.R.Janeiro, 42 (4): 235-243, 1975. 
28. MANZANEDO, G.H. - Estudio sociocultura.l sobre integraciōn de los sistemas de salud y participaciōn de la comunidad. Bol.ofic.sanit.panamer., 84..(3): 196-206, 1978.

29. MARQUES, R.M. et al. - Crescimiento.de niños brasileños. Peso y altura, segun idad y sexo, influencia de factores socioeconomico, Washington, D.C., Organizacion Pa namericana de la Salud, 1975 (OPAS - Publ.cient., 309).

30. MCLAREN, D.S. et al. - A simple scoring sistem for classi flying the severe forms of protein-calorie malnutrition of early childhood. Lancet, 1 (7489): 533-535, 1967.

31. MENCHU, M.T.et.al.-. Efecto del nivel socio-economico de la familia sobre la dieta del niño preescolar. Arch. lat.amer.Nutr。, 23 (3): 305-324, 1973 .

32. METODOLOGIA para la formulación de politicas nacionales de alimentación y nutrición y su ejecución intersecto rial. Bol:ofic.sanit.panamer., 80 (6): 478-497, 1976 .

33. MILLER, D.C. et a1. - Simplified field assessment of nutritional status in early childhood: pratical suggestions for developing countries. Bull. wed.Hlth.0rg., 55 (1) : $79-86,1977$.

34. NELLHAUS, G. - Head circunference from birth to eighteen years. Pediatrics, 41 (1): 107-113, 1968 . 
35. :ORGANIZACION MUNDIAL. DE SALUD..... Camite de Expertos en Eva luación Medica del Estado de Nutriciōn. Ginebra, 1962. Informe. Ginebra, 1963-(OMS - Ser.inf.tecn。, 258).

36. PINES, J.M. - El lenguaje de la planificación nutriciona1. Alim.Nutr., 3. (3): 19-21, 1977 .

37. POPOVIC,A.M. et al. - Marginalização-cultural uma me todologia -para seu estudo..Cad.Pesq...(7): 11-60,1973.

38. PUFFER, R.R。\& SERRANO, C.V. - Caracteristicas de la mortalidad en la niñez, informe de la Investigación Interamericana de mortalidade en la ninez. Washington, D.C., Organización Panamericana de la Salud, 1973. (OPAS - Publ.cient。, 262)。

39. PUfFER, R.R。 \& SERRANo, C.V。 - La deficiencia nutricionat y la mortalidad en la niñez. Resultado de la investigación interamericana de mortalidad en la niñez. Bul.Ofic.sanit.panamer., 75. (1): 1-30, 1973.

40. ROSADO, M.S. - Procedimientos para la movilización de la comunidad en los programas de salud publica. Salud publ.Mex., 10 (4): 453-457, 1968.

41. SCHUfTAN, C. et al. - Bajo rendimiento escolar: desnutriciōn o deprivación cultura1? Arch.lat.amer. Nutr., 25 (2): $121-134,1975$.

42. SEOANE, N。\& LATHAN, M.C. - Nutricional anthropometry 
in the identification of malnutrition. in childhood. J.Trop.Pediatr., 17 (3): 98-103, 1971 .

43. SIEGEL, S. - Nomparametric statistic for the behavioral sciences. N. York, McGraw-Hill, 1956.

44. SIL.VA, A.C. - Pobreza, desenvolvimento mental e desempenho escolar. Cad.Pesq. (29): 8 - w, 1979.

45. SINGER, P.I. - "Mais pobres e mais ricos". Opinião. (116), 24. de jan., 1975. p. 4 .

46. SITUACION nutricional y alimentaria en los paises de America Latina y el Caribe. Bol. (tc.sanit.panamer., 80 (6): 498-528, 1976 .

47. TICAS, J.M. - Las mezclas alimenticias de alto valor nutritivo y bajo costo en la lucha contra la desnutricion proteico-calorica. Bol. or.c.sanit.panamer., $\underline{85}(1): 26-39,1978$.

48. UDAMI, P.M. et al. - Mental development in severe protein calorie malnutrition. Indian Pediat., 13 (7): $507-516,1976$.

49. VILLEGAS, H. - Costa Rica: recursos humanos y participación de la comunidad en los servicios de salud en e1 medio rura1. Bol...6esanit,panamer., 84 (1): 1323, 1978 . 
50. VITERI, F- et a.1. - Métodos de evaluaciōn del estado nú tricional proteinico-calorico en preescolar de condi ciones socio-economicas diferentes: recuperación nu tricional del sarampion en niños cronicamente alimen tados. Arch,lat.amer.Nutr., 23 (1): 13-32, 1973.

51. WATERLOW, J。C. - Classification and definition of protein -calorie malnutrition. Brit.med.J., 3: 566-569, 1972.

52. WATERLOW, J.C. - Note ou the assement and classification of protein energy malnutrition in children. Lancet. $\underline{2}(7.819): 87-89,1973$.

53. YUNES, J.\& MARCONDES, E. - Classificação da desnutrição..Rev.Hosp.clin., 30 (6): 484-489, 1975 .

54. ZACCHI, M.A. - Comunicação pessoal, 1978. 
$\begin{array}{lllll}\text { A } & N & E & X & O\end{array}$ 
Ifffluêncla exerclda por um Programa de Educação Alimentar sobre o estado nutricional de crlanças pré-escolares que recebem Suplementação Mlimentar no Município de Carapicuiba

Posto FORMULARIO NG

- Abordagem

1 - Nome do entrevistado

2 - Caracterização da ?ainflia e renda

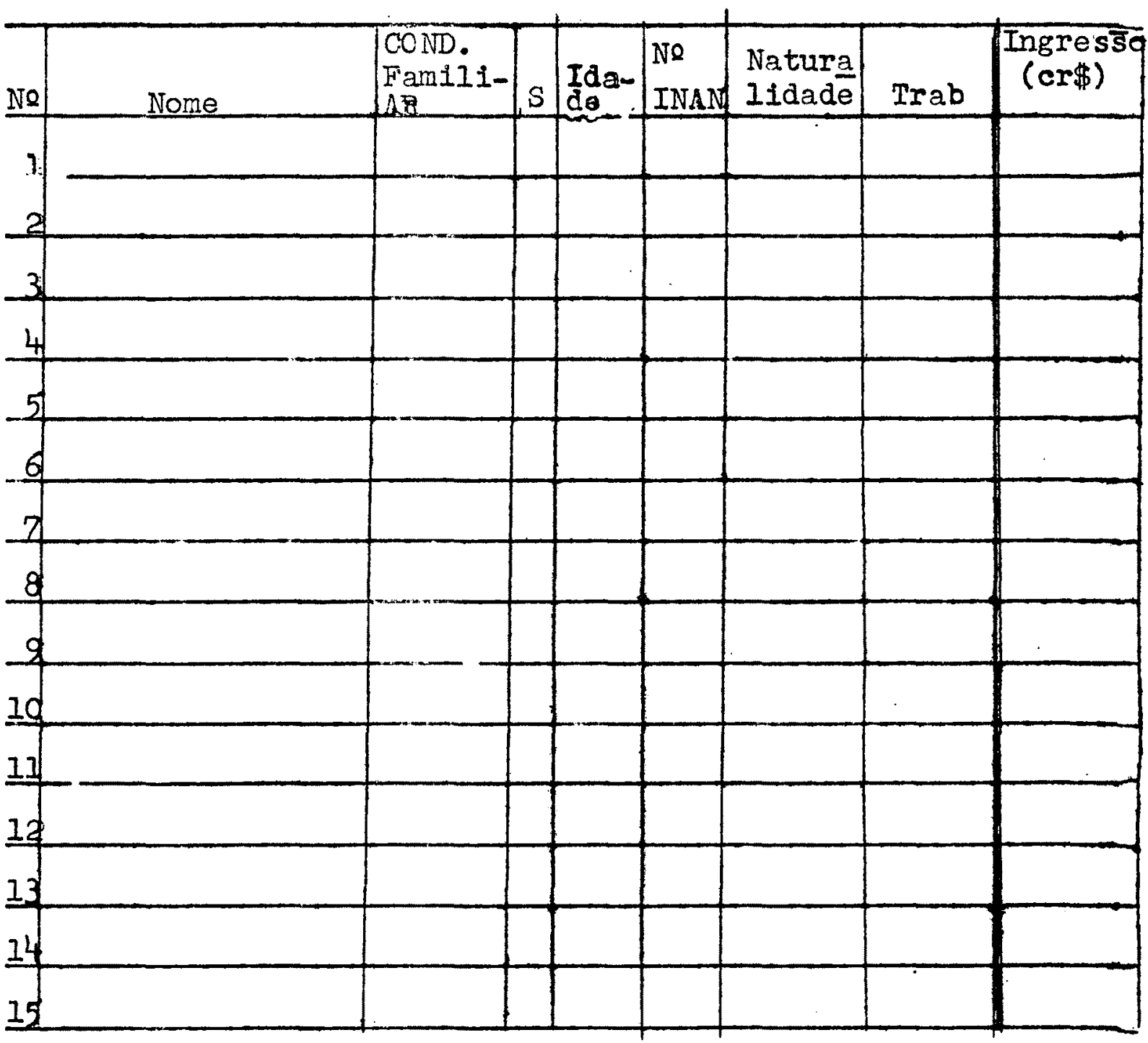




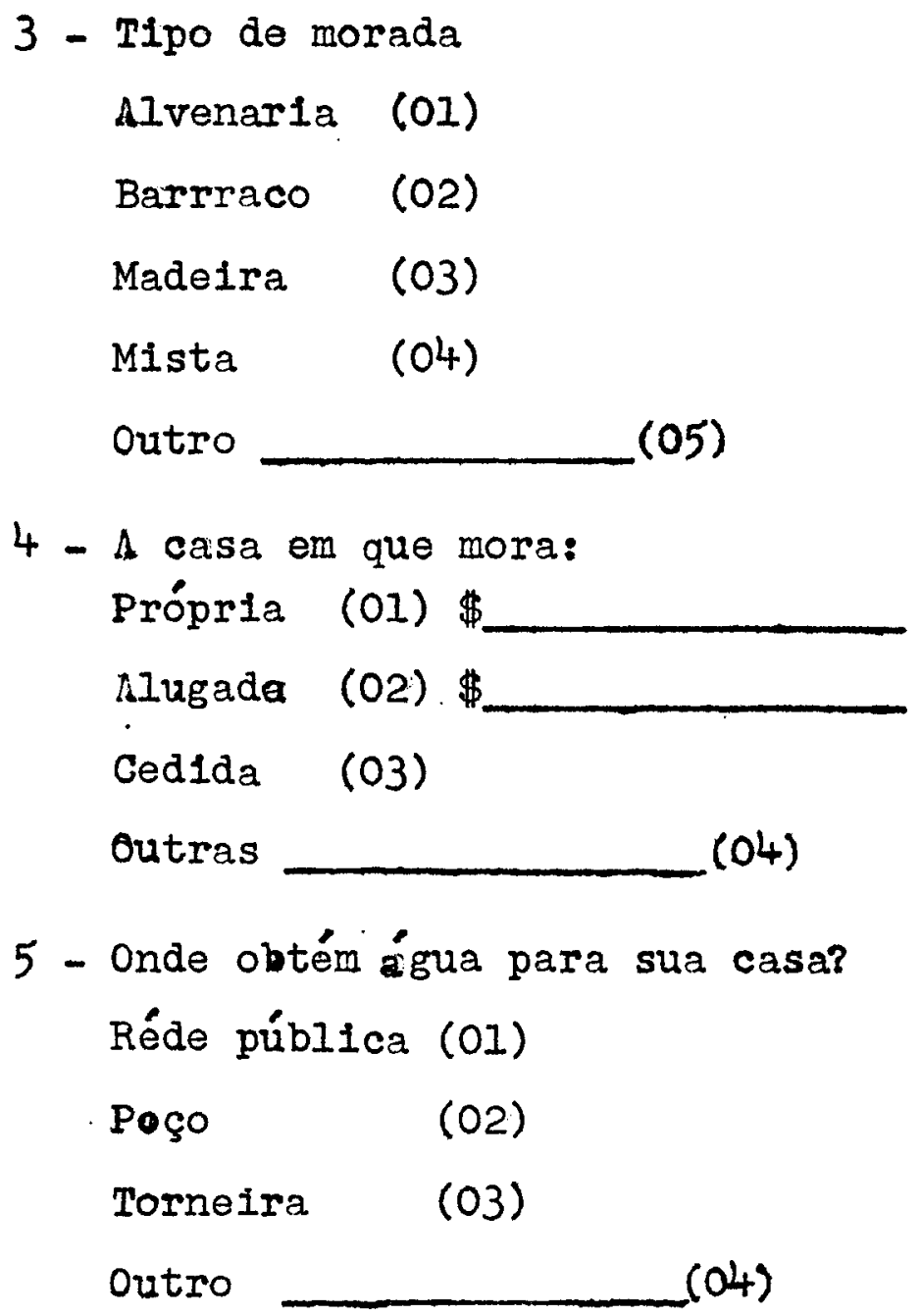

$6: 0$ que a sra. faz com a água que usa para beber? Flitra ()

Ferve ()

clora ()

Não faz nada ( )

Outros ( )

7 - Para onde val o esgoto de sua casa?

Fossa $(;()$

Esgoto da rua ( )

Campo aberto ( )

Outros ()

não sabe ( ) 
8 - Escolaridade do pal ou responsável e da mầe

Escolaridade Pail ou

1. Sem escolaridade

2. 10 grau incompleto

3. Io rau completo

4. 20 grau incompleto

5. 20 grau completo

6. Superior incompleto

2. Superior completo responsável

Måo

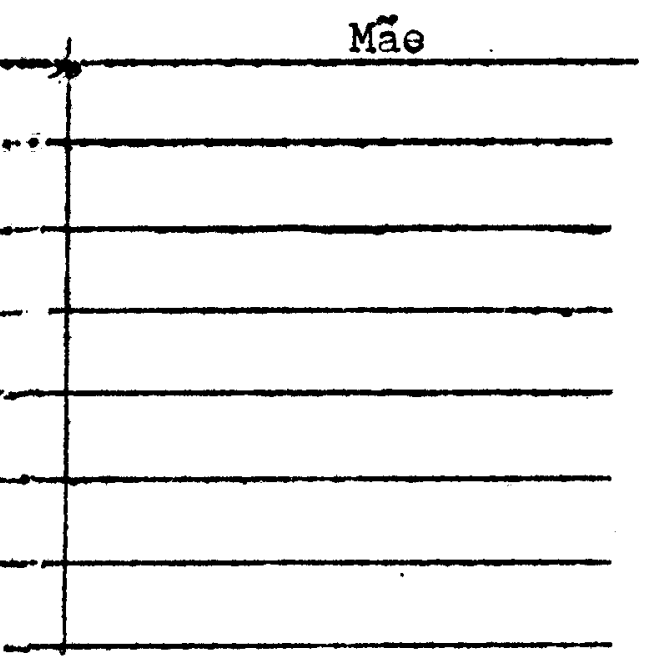

9 - Ocupação do pai ou responsável

10 - Gostaria que a sra.informasse, destes alimentos quals a sra. costima comprar ? (Checar e definir quantidade e frequên cia)

\begin{tabular}{|c|c|c|c|}
\hline Alimento & Checagem & $\begin{array}{l}\text { quantidade } \\
\text { semanal }\end{array}$ & obsospagsan \\
\hline \multicolumn{4}{|l|}{ ovos } \\
\hline \multicolumn{4}{|l|}{ Ieite } \\
\hline \multicolumn{4}{|l|}{ queijo } \\
\hline \multicolumn{4}{|l|}{ carne vaca } \\
\hline \multicolumn{4}{|l|}{ carne porco } \\
\hline \multicolumn{4}{|l|}{ miúdos } \\
\hline \multicolumn{4}{|l|}{ peixe } \\
\hline \multicolumn{4}{|l|}{ frango } \\
\hline \multicolumn{4}{|l|}{ acúcar } \\
\hline \multicolumn{4}{|l|}{ óleo } \\
\hline \multicolumn{4}{|l|}{ banha } \\
\hline \multicolumn{4}{|l|}{ margarina } \\
\hline \multicolumn{4}{|l|}{ felfão } \\
\hline \multicolumn{4}{|l|}{ arroz } \\
\hline \multicolumn{4}{|l|}{ farinha de trigo } \\
\hline \multicolumn{4}{|l|}{ pão } \\
\hline massas & & & \\
\hline
\end{tabular}




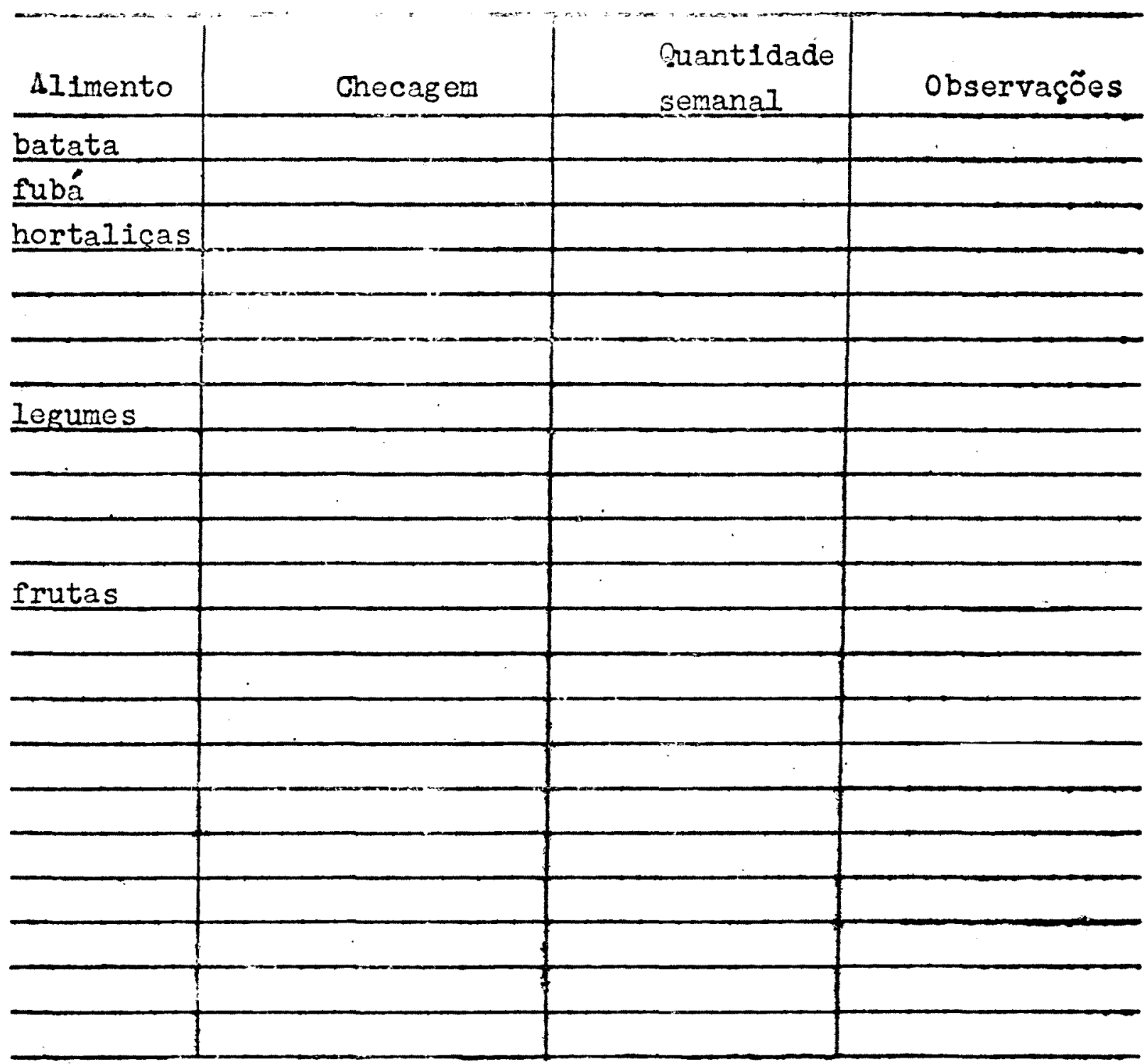


11 - Quantas pessoas comem em sua casa?

café da manhã

almoço

merenda

jantar

12 - A sra. tem quintal em sua casa?

sim ( ) Não ( ) (passe p/a perg. 18)

13 - 1. Tem horta? ( ) 5.2 e $3($ )

2. Pomar ( ) 6.1,2 e $3($ )

3. Crıação ( ) 7. não utiliza 0 quintal ( )

4. $1 \cdot 2()$

14 - Que criacão $\quad$ oue verdura

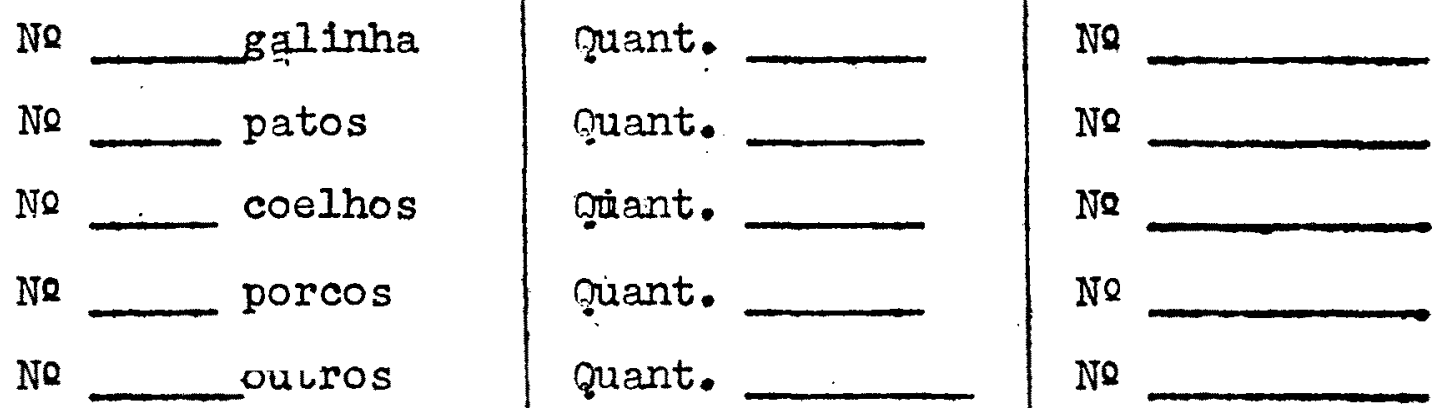

I5 D-que a sra. faz com os produtos?

\begin{tabular}{l|l|l|l} 
& Horta & Pomar & Criaçäo \\
\hline vende & & & \\
\hline consomo & & & \\
\hline ambos & & & \\
\hline
\end{tabular}

16 - Dessas verduras quals a sua famflia ma1s come?

17 - Dessgs frutas quais suas famflias mais come? 
18 - 1 sra. já recebeu alguma noçắo sobre AlImentação ?

$$
\text { sim () não () - passe para perg. } 20
$$

19 - De quem ?

médico

mutricionista (02)

atendente do Posto (03)

ou do Hospital

voluntaria (04)

outros (05)

20 - Por que a sra. acha que nos alimentamos?

para ranter a saúde (OI)

para viver (02)

para não sentir fome (03)

para ficar forte (04)

outros (05)

21 - 0 que a sra. acha do ovo na alimentação $i$

22 - Por que?

23 - Qual ou quais as partes do ovo que a sra. acha que é meIhor para a saúde de seu filho?

gema ( ) $\operatorname{clara}()$ ambas ()

24 - Por que?

é mas forte

(OI)

tem mais vitaminas (02)

é tudo igual (03)

não sabe (04)

outros (05)

25 - 0 quie a sra. acha da carne na alimentação ?

26 - Por que ? 
27 - Carne de que animals a sra. acha que é a melhor para a saú de de seu filho's

$\begin{array}{ll}\text { carne de boi } & (01) \\ \text { carne de aves } & (02) \\ \text { carne de porco } & (03) \\ \text { carne de peixes } & (04) \\ \text { todas as carnes } & (05) \\ \text { outras } & (06)\end{array}$

28 - A sra. acha que existe diferença entre a carne de 1 a $e$ de 2 a para a saúde de seu filho?

sim ( ) não ( ) - passe para a perg. 30

29 - gual ?

carne de 1a (01)

carne de $2^{a}$ (02)

30 - Por que?

31 - O que sra. acha das frutas na alimentação?

32 - Por que ?

33 - 0 que a sra. acha das verduras e legumes na alimentaçăo?

34 - Por que? 
35 - Em quais alimentos a sra. acha que encontramos mais vitaminas?

carnes

verduras (04)

ovos

legumes (05)

leite

(03)

frutas (06)

outros (07)

36-que tipo de Ieite a-sra. está roceboedo aqui ?

Leite em pó desinatado

leite em pó integral

leite en pó

não sabe

outros

37 - $\Lambda$ sra. sabe para que serve este leite que a sra. recebe para seu filho?

para alimentar.

faz bem para a saúde

para fortifl car

para o crescimento e desenvolvimento da criança (04) não sabe

outros

38 - A sra. recobeu algum folheto sobre o leite que a sra. re. cebe aqui?

$\operatorname{sim}()$ não $($ )

39 - A sra. recebeu alguma orientação sobre o preparo desto le1 te ?

sim ( ) não ( ) - passe para perg. 42

40 ouem orientou?

- voluntária

- outros

(02)

41 - qual foi a orientação dada ?
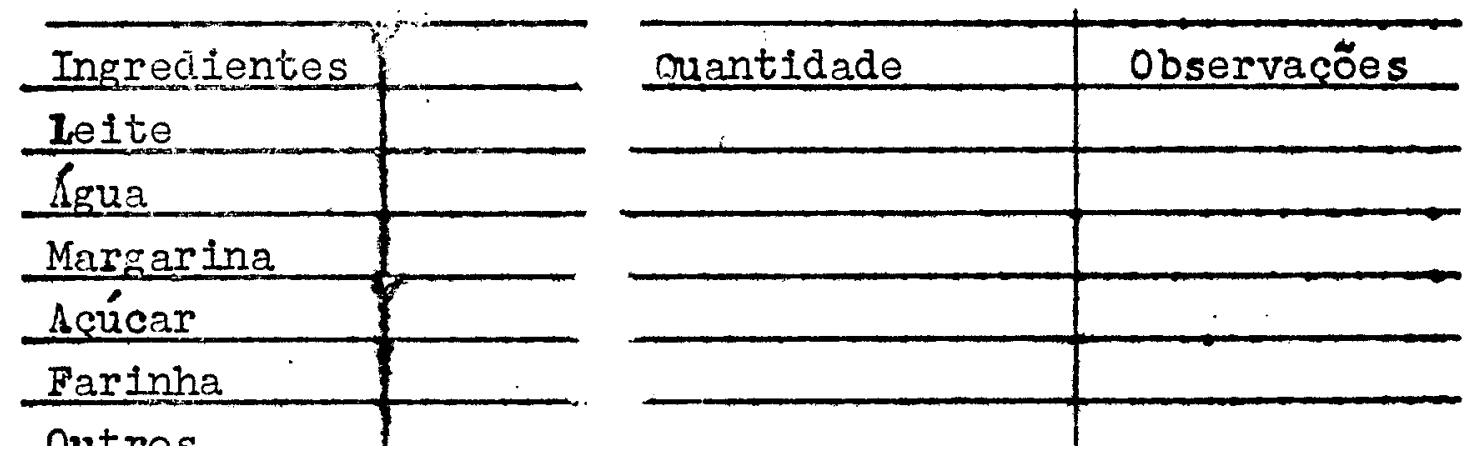
42 - A sra. costuma dar leite com frutas para seu filho ? $\operatorname{sim}()$ não ( ) (passar para a perg. $(4+4)$

43 - Quais são as frutas que a sra. costuma misturar com leite?.

44 - quais são as fmutas que a sra. não mistura com leite?

\begin{tabular}{|l|l|}
\hline Frutas & \multicolumn{2}{|c|}{ Por que ? } \\
\hline & anotar o motivo mais importante) \\
\hline & \\
\hline & \\
\hline & \\
\hline & \\
\hline & \\
\hline & \\
\hline & \\
\hline & \\
\hline
\end{tabular}

45- A sra. acha que comer putros alimentos misturados faz mal para a saúde de seu filho?
$\operatorname{sim}$
não ()
(passe para perg 47) 
46 - quals såc os alimeztos que mlsturados fazem mal para a s saúde de set filino ?

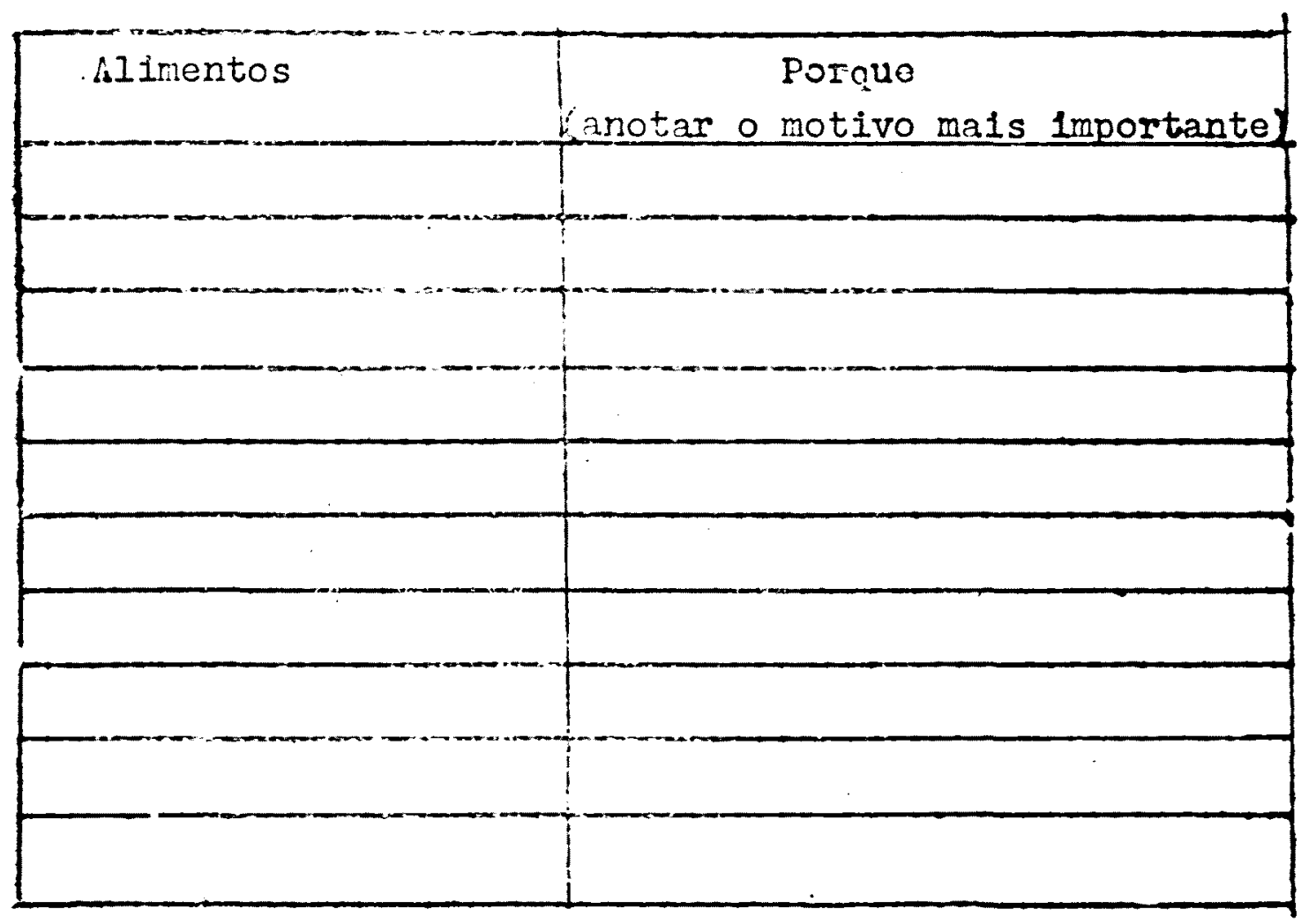

47 - quando seu filho está com diarréia que alimentos a sea. não dis?

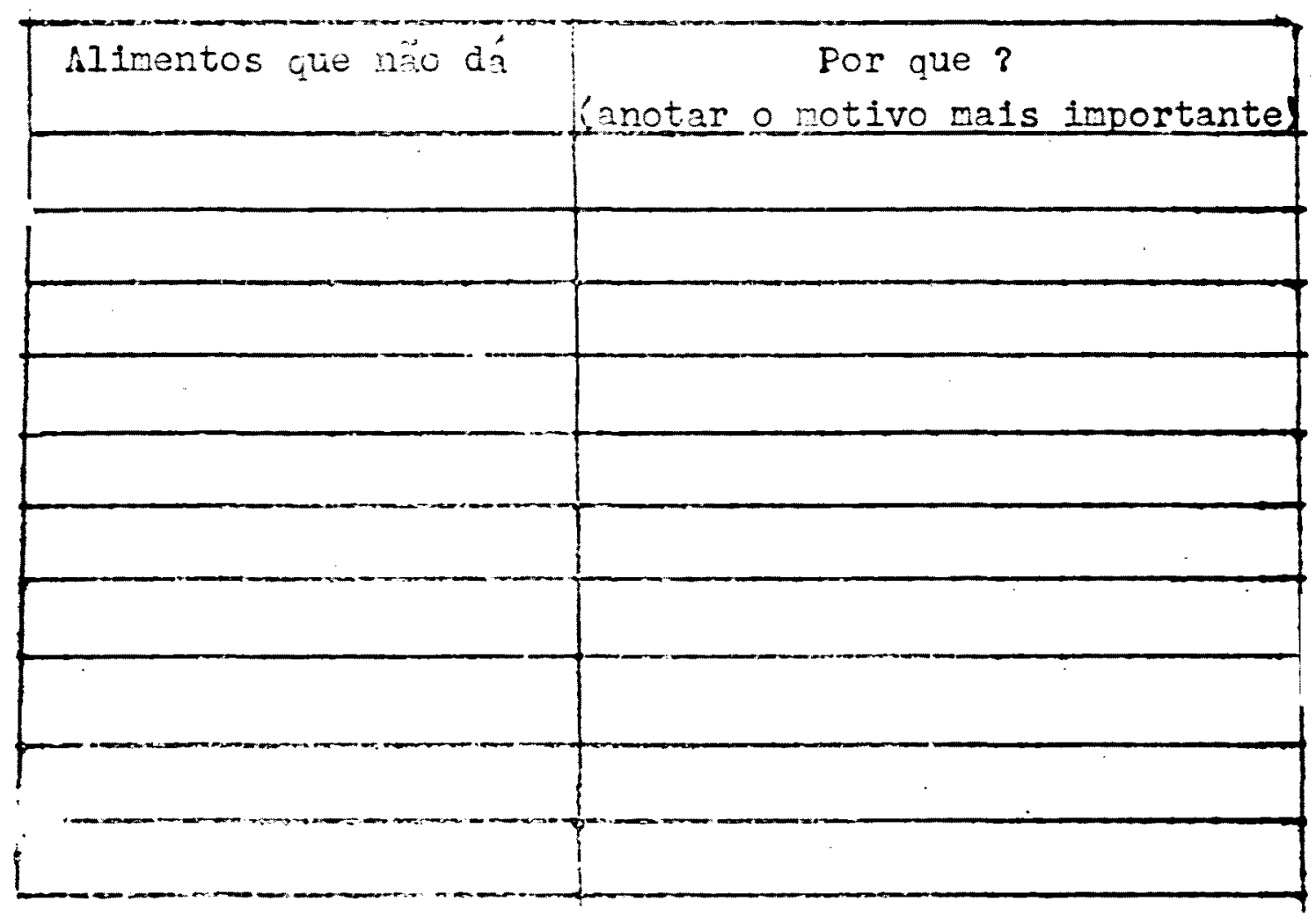


48 - Cono a sra. psepara o leite que a sra. recebe aqui?

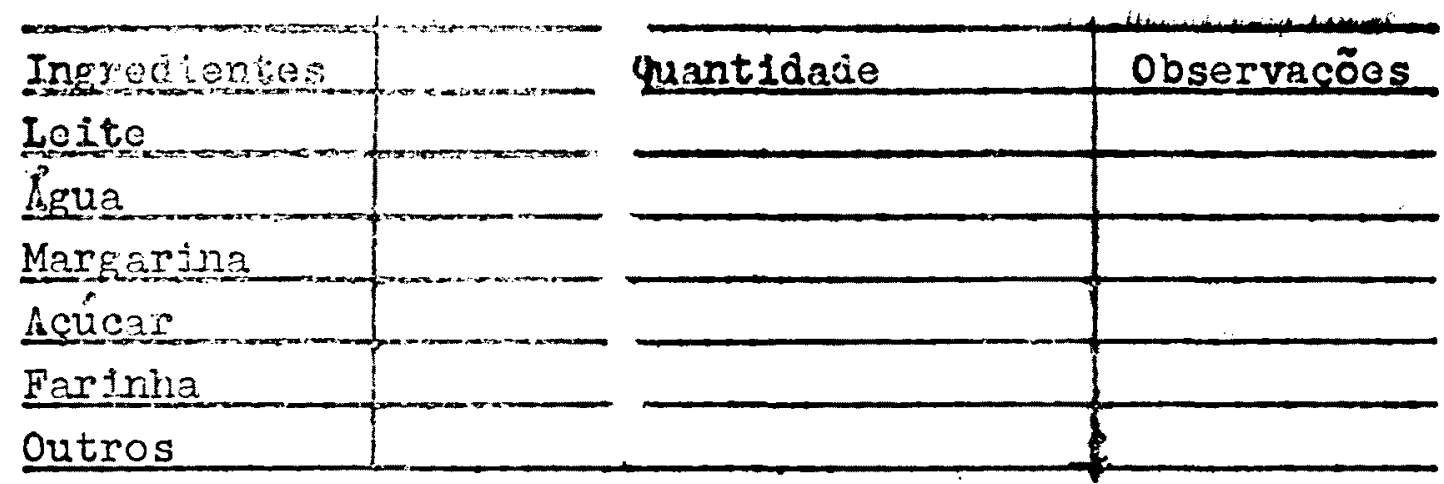

4\% - Para quantas pessuas dá esta quantidade de le1te prepara do?

50 - Quantas vezes por dĩ a sra. prepara esta quantidade ?

1 vez por dia (OI)

2 vezes por dia 02

3 vezes ou mais po: dia (03)

51 - Na sua casa, quem toma este leite?

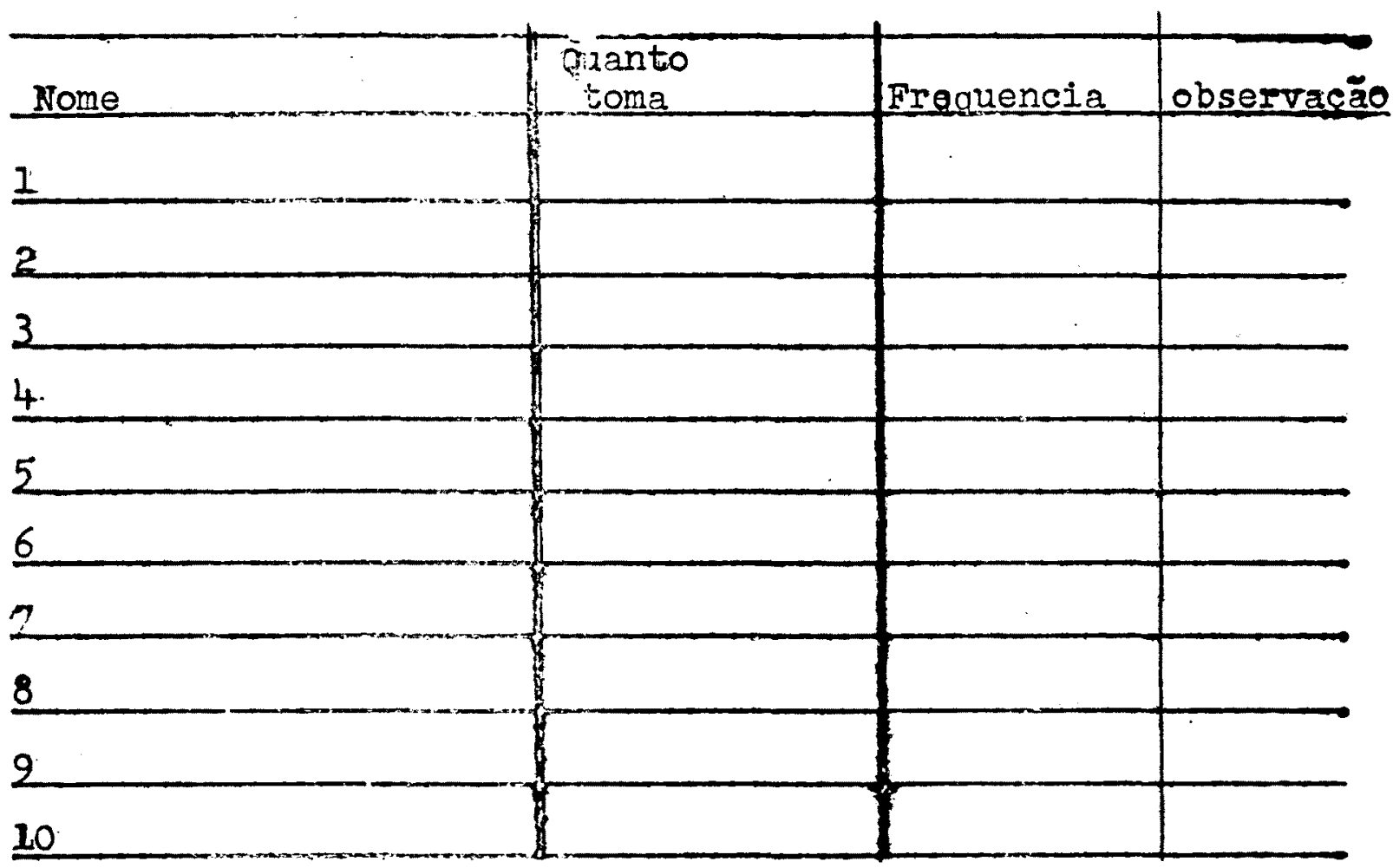

52 - quarto tempo bia, en média, a quantiazde de leite que a sra, recebe aqui "s

$\begin{array}{ll}\text { até } 7 \text { dias } & \text { (01): } \\ \text { de } 8 \text { a } 14 \text { dias } & \text { (02) } \\ \text { de } 15 \text { a } 21 \text { dias } & (03) \\ \text { de } 22 \text { a } 30 \text { dias } & \text { (04) } \\ \text { mais de } 30 \text { dias } & \text { (05) }\end{array}$


53 - Se a sra. pudesse comprar qualquer tipo de alimento, 0 que ara. compraria?

Data Entroolistodor 
FORMULARIO CLINICO Ne

LOCAL

NOME

Oo Data de nascim.

01 Idade

02 Sexo (1) (2)

ANTECEDENTES PERINATAIS

030 seu filho nasceu em:

Hospital

(I)

Casa

04 Ordem de nascimento
(1) (2) (3) (4) (5)

05 Peso ao nascer

.

06 Estatura ao nascer

cm.

DESENTOLVIMEITO

07 Sentou meses

08 sndou meses

ALEITAMENTO

090 seu fliho fol amamentado?

sim (1) (passe para perg. 10 e 11A).

nåo (2) (passe para pergunta 11 B)

10 Até que ldade ? meses

11 Parou ou não amamentou por:

Não sabe

A B

Nova gestação

(2) (2)

(2) (8)

Quantidade insuficiente

(3) (3)

Le1te fraco

(4) (4)

Trabalhava fora

(5) (5)

Recomendação médica

(6):(6)

0 filho não aceitou

(7) (7)

Outro

12 A que idade o Inicio da ablactaçãos 
INTERCORRENCTAS

( $A=$ atualmente, $R=$ recente, $R^{\prime}=$ recurrente)

13 Aparelho respiratório

, (2) (2) (3)

14 Diarréia

(1) (2) (3)

15

() (.) 15

EXAME FISICO

16 Antropometrila:

Reso $\left(\mathrm{K}_{\mathrm{g}}\right)$

Estatura (cm)

Perĺmetro cefálico (cm)

Perímetro braquial $(\mathrm{cm})$

17 Sinais clenicos:

Cabelo

Tireó1de

Pele

Abdemem

Olhos

Subcutáno

Boca

Osteomuscular

Obsorvaçōes:

Data

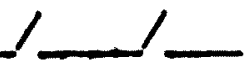

